\title{
Mesenchymal Stem Cell-Derived Extracellular Vesicles in Liver Immunity and Therapy
}

\author{
Ruiqi $\mathrm{Wu}^{\dagger}$, Xiaoli Fan ${ }^{\dagger}$, Yi Wang, Mengyi Shen, Yanyi Zheng, Shenglan Zhao \\ and Li Yang *
}

Sichuan University-University of Oxford Huaxi Joint Centre for Gastrointestinal Cancer, Department of Gastroenterology and Hepatology, West China Hospital, Sichuan University, Chengdu, China

\section{OPEN ACCESS}

Edited by:

Rachel Elaine Hewitt,

University of Cambridge,

United Kingdom

Reviewed by:

Shao-wei Li,

Taizhou Hospital of Zhejiang Province

Affiliated to Wenzhou Medical

University, China

Andrea Henriques-Pons,

Oswaldo Cruz Foundation (Fiocruz),

Brazil

*Correspondence:

Li Yang

yangli_hx@scu.edu.cn

${ }^{\dagger}$ These authors have contributed equally to this work and share first authorship

Specialty section:

This article was submitted to Immunological Tolerance and Regulation,

a section of the journal

Frontiers in Immunology

Received: 12 December 2021 Accepted: 15 February 2022

Published: 04 March 2022

Citation:

Wu R, Fan X, Wang Y, Shen M, Zheng $Y$, Zhao $S$ and Yang $L$ (2022)

Mesenchymal Stem Cell-Derived

Extracellular Vesicles in Liver

Immunity and Therapy.

Front. Immunol. 13:833878.

doi: 10.3389/fimmu.2022.833878
Mesenchymal stem cells (MSCs), as the most common cell source for stem cell therapy, play an important role in the modulation of innate and adaptive immune responses and have been widely used in clinical trials to treat autoimmune and inflammatory diseases. Recent experimental and clinical studies have shown that MSC-derived extracellular vesicles (MSC-EVS) can inhibit the activation and proliferation of a variety of proinflammatory cells, such as Th1, Th17 and M1 macrophages, reducing the secretion of proinflammatory cytokines, while promoting the proliferation of antiinflammatory cells, such as M2 macrophages and Tregs, and increasing the secretion of anti-inflammatory cytokines, thus playing a role in immune regulation and exhibiting immunomodulatory functions. Besides MSC-EVs are more convenient and less immunogenic than MSCs. There is growing interest in the role of MSC-EVs in liver diseases owing to the intrinsic liver tropism of MSC-EVs. In this review, we focus on the immunomodulatory effects of MSC-EVs and summarize the pivotal roles of MSC-EVs as a cell-free therapy in liver diseases, including NAFLD, AlH, acute liver failure, liver fibrosis and hepatic ischemia-reperfusion injury. Moreover, we provide a concise overview of the potential use and limits of MSC-EVs in clinical application.

Keywords: extracellular vesicles, mesenchymal stem cell, immunomodulation, liver diseases, drug delivery system

\section{INTRODUCTION}

Liver diseases, with their high morbidity and mortality rates, pose a significant risk to human health and, consequently, a heavy economic burden (1). Stimulation such as viral hepatitis, drugs, and alcohol abuse can trigger chronic/acute liver injury and inflammation that can lead to liver failure, cirrhosis, and even hepatocellular carcinoma (2). Currently, treatments are limited for many liver diseases, such as non-alcoholic fatty liver disease (NAFLD) and acute liver injury. In regard to cirrhosis and liver failure, orthotopic liver transplantation is the only effective treatment (3). Therefore, novel and effective treatments are urgently needed.

As nonhematopoietic pluripotent stem cells, MSCs are capable of self-renewal and differentiation. Numerous studies have shown that MSCs can effectively inhibit the activation of innate immune system cells, including macrophages (4), dendritic cells (DC) (5), natural killer cells (NK) (6), monocytes (7) and others. MSCs also inhibit the activation of adaptive immune cells, 
including T cell subsets (8) and B cell subsets (9). Thus, MSCs show a significant effect on immune modulation. As the central metabolic organ and important immune participant of the human body, the liver has a high density of myeloid and lymphoid immune cells, and many liver diseases are related to the destruction of liver immune homeostasis (10). Recent clinical studies have demonstrated that MSC therapy alleviates liver damage, improves liver function, and promotes liver tissue regeneration $(11,12)$.

Currently, it is generally believed that MSCs exhibit immunomodulatory functions mainly through the paracrine pathway, among which, extracellular vesicles (EVs) are the most appealing components. EVs are vesicles secreted by cells with phospholipid bilayer membrane, and are capable of mediating intercellular communication by transferring membrane and cytosolic proteins, lipids, and RNAs (13). Compared with MSCs, MSC-EVs are much smaller in size and easier to obtain and store. When injected intravenously in vivo, MSC-EVs mainly accumulate in liver (14), and liver diseases have close relationship with immune homeostasis imbalance, which fits perfectly with the function of MSC-EVs. Therefore, the scientific community has examined the application of MSC-EVs instead of MSCs in liver diseases. In this review, we summarize the effects of MSC-EVs on liver immunity and diseases, outline the limits of MSC-EVs in clinical application, and propose potential applications in the future.

\section{OVERVIEW OF MSCS}

Mesenchymal stem cells (MSCs), also mentioned as multipotent stromal cells or mesenchymal stromal cells, are multipotent cells present in almost all forms of postnatal organs and tissues (15). MSCs were initially discovered by Alexander Friedenstein approximately 50 years ago (16), and were originally named by Caplan in 1991 (17). In early clinical experiments, MSCs were mainly isolated from bone marrow, cartilage, and fat tissues (18),

\footnotetext{
Abbreviations: MSC, mesenchymal stem cell; EV, extracellular vesicle; NAFLD, non-alcoholic fatty liver disease; DC, dendritic cell; NK, natural killer; HLA, human leukocyte antigens; IFN- $\gamma$, interferon- $\gamma$; TNF- $\alpha$, tumor necrosis factor- $\alpha$; TLR, Toll-like receptor; LPS, lipopolysaccharide; ISEV, International Society for Extracellular Vesicles; Hsp, Heat-shock protein; IL, Interleukin; TGF- $\beta$, transforming growth factor $\beta$; PBMC, Peripheral blood mononuclear cell; APC, antigen-presenting cell; LSEC, hepatic sinusoidal endothelial cell; KC, Kupffer cell; APP, acute-phase protein; CRP, C-reactive protein; SAA, serum amyloid A; NKT, Natural killer T; HBV, hepatitis B virus; HCV, hepatitis C virus; Tfh, follicular helper T; Treg, regulatory T; Tc, cytotoxic T; PGE2, Prostaglandin E2; 15d-PGJ2, 15deoxy- $\Delta 12,14$-prostaglandin J2; DAMPs, damage-associated molecular patterns; HMGB1, high mobility group protein 1; NLRP3, NOD-like receptor family, pyrin domain containing 3; NAFL, nonalcoholic fatty liver disease; NASH, nonalcoholic steatohepatitis; AIH, autoimmune hepatitis; MPO, myeloperoxidase; FXR, farnesoid X receptor; ALT, alanine aminotransferase; AST, aspartate aminotransferase; MyD, myeloid differential protein; TRAF6, TNF receptor associated factor 6; AMPK, AMP-activated protein kinase; CYP2D6, cytochrome P450 2D6; ConA, Concanavalin A; HGF, hepatocyte growth factor; ALF, acute liver failure; ECM, extracellular matrix; HSC, hepatic stellate cell; $\alpha$ SMA, $\alpha$-smooth muscle actin; MMP, matrix metalloproteinase; IRI, ischemiareperfusion injury; ROS, reactive oxygen species; $\mathrm{BBB}$, blood-brain barrier; DEX, dexamethasone; MPS, mononuclear phagocyte system.
}

recently, they were also isolated from the umbilical cord, placenta, muscle, dental pulp, liver, and other tissues (19). Although MSCs from different origins share similar marker profiles and cell phenotypes, the epigenetic characteristics of MSCs from different tissues show significant differences in gene expression patterns, proteome, and function, which are only related to their source $(20,21)$. Without stimulation, cultured MSCs uniformly showed the morphology of plastic adherent cells (fibroblast-like cells), and expressed stromal surface markers (such as CD73, CD90, and CD105), but lacked hematopoietic cell markers [such as CD11a, CD14, CD19, CD45 and human leukocyte antigen (HLA)-DR]. Consequently, they can differentiate into adipogenic, chondrogenic, and osteogenic lineages (22).

Several preclinical studies have shown that MSCs can modulate the activation and function of various immune cells in the innate and adaptive immune systems. However, the immunomodulatory capabilities of MSCs are not constitutive and depend on the exposed inflammatory environment. In the presence of high levels of proinflammatory cytokines [such as interferon- $\gamma$ (IFN$\gamma$ ) and tumor necrosis factor- $\alpha$ (TNF- $\alpha)$ ] or activation of Toll-like receptor 3 (TLR3) ligands, MSCs mediate immunosuppression (23). For example, MSCs inhibit the proliferation and activation of $\mathrm{T}$ cells (24), induce the proliferation of regulatory $\mathrm{T}$ (Treg) cells (6), inhibit the proliferation of stimulated B cells and their differentiation into antibody producing cells (plasma blasts) (25), and promote polarization towards an immunomodulatory M2 phenotype (26). On the other hand, during the early phase of inflammation with low levels of inflammatory cytokines or activation of TLR4 by low levels of lipopolysaccharide (LPS), MSCs show proinflammatory effects through the secretion of chemokines that recruit lymphocytes to the sites of inflammation. Conclusively, MSCs show immunosuppressive functions in the vigorous inflammatory environment (27).

Due to the functions of immune modulation and promotion of cell survival, as well as easy access and efficient proliferation in vitro, MSCs have been increasingly used as cell therapy in clinical trials focused on tissue repair and regeneration. However, contrary to predictions, a large number of preclinical studies have shown that MSCs are not transplanted into tissues in significant numbers after infusion, while the duration of transplantation is insufficient $(28,29)$. Currently, numerous evidence supports the therapeutic and immunomodulatory functions of MSCs partly but significantly dependent on paracrine effects and secretory components $(30,31)$. Thus, researchers turned their attention to paracrine secretions such as EVs.

\section{OVERVIEW OF EXTRACELLULAR VESICLES}

Extracellular vesicles(EVs)are particles naturally released from the cell, delimited by a lipid bilayer and cannot replicate (32). They can be classified into two major categories, ectosomes, and exosomes. Ectosomes are plasma membrane-derived vesicles ranging from $50 \mathrm{~nm}$ to $1 \mathrm{~mm}$ in diameter. In contrast, 
exosomes originate from endosomes and are in a size range of $\sim 40$ to $160 \mathrm{~nm}$ in diameter ( $100 \mathrm{~nm}$ on average) (33). According to the position statements of the International Society for Extracellular Vesicles (MISEV2014 (34) and updated MISEV2018 (32)), evidence of endosomal biogenesis, such as findings of EVs caught in the act of release by live imaging techniques, is required to classify the extracellular vesicles in the research as an "exosome". Therefore, ISEV recommended other classifications based on physical characteristics or biochemical composition. Depending on the size of vesicles, those $<100 \mathrm{~nm}$ or $<200 \mathrm{~nm}$ are classified as "small EVs" (sEVs) and those > $200 \mathrm{~nm}$ are classified as "medium/large EVs" (m/l EVs), among which, sEVs are considered to be more consistent with the definition of therapeutic EVs. Therefore, we use "extracellular vesicles (EVs)" as an acronym for "exosomes" in this review. Their membranes are rich in cholesterol, sphingomyelin, and hexose ceramide, especially highly mannosylated epitopes, lectins and tetraspanin-enriched microdomains, compared with parent cells (35-37). EVs contain large amounts of proteins, such as heatshock proteins (Hsp70 and Hsp90) (38), genetic elements, such as mRNAs and miRNAs (39), and cytokines such as TNF- $\alpha$, interleukin (IL)-2, IL-6, IL-8, IL-10, etc (40). By transmitting their contents through receptor-ligand interactions, endocytosis or direct fusion to the cell membrane, EVs can mediate and regulate a variety of cellular processes in target cells (41).

\section{Functions of MSC-Derived Extracellular Vesicles in Immunity}

EVs are found in nearly all body fluids and are released by almost all types of cells in the human body, and can be isolated from cells, plasma, tissue sources, milk and even plants. Among them, cellderived EVs are the most easily obtainable in large quantities. MSCs are one of the most easily obtained primary stem cells in the human body and secrete large amounts of EVs, which makes MSCs one of the ideal sources of EVs. In addition to CD107, CD63 and CD81, markers for EVs, MSC-EVs also express markers for MSCs, such as CD29, CD73, CD90 and CD44 (42). MSC-EVs play an important role in the regulation of the immune system. MSCEVs carry bioactive molecules, such as mRNAs and miRNAs, cytokines, chemokines, immunomodulators, and growth factors, thereby modulating the balance between the immune response and immune tolerance (Figure 1).

MSC-EVs can influence innate immune cells such as macrophages, DCs and NK cells, thus modulating the innate immune response. Depending on the specific stimulus, macrophages polarize into different phenotypes, express different markers, and perform different functions. Murine macrophages can be classified into the M1 phenotype and M2 phenotype. While for human macrophages, their various phenotypes form a continuous spectrum without clear boundaries and they can switch into other phenotypes under different stimulations (43). For murine macrophages it is currently believed that TLR ligands (such as LPS) and proinflammatory cytokines (such as IFN- $\gamma$ and TNF- $\alpha$ ) induce the differentiation of M1 macrophages, while Th2 cytokines, such as IL-4 and IL-13, induce the differentiation of M2 macrophages (44). M2 macrophages produce antiinflammatory cytokines such as transforming growth factor $\beta$ (TGF- $\beta$ ), IL-1 receptor antagonist (IL-1RA), and IL-10 (45). MSC-EVs can promote the M2-type polarization of macrophages to regulate the immune response, which is related to the miRNAs contained, such as miR-132 (46), miR21 (47), and miR-21-5p (48).MSC-EVs can inhibit the maturation of DCs, reduce the secretion of proinflammatory factors (49).. MSC-EVs are rich in miR-21-5p, which can reduce the migration of DCs to the CCR7 ligand CCL21, and is associated with reduced expression of CCR7 protein and decreased production of proinflammatory cytokines (50). Moreover, MSC-EVs can also inhibit the function of NK cells (51) and inhibit the proliferation of peripheral blood mononuclear cells (PBMCs) (52).

In addition, MSC-EVs control the proliferation and differentiation of $\mathrm{T}$ cells and $\mathrm{B}$ cells, modulating the adaptive immune response. $\mathrm{T}$ cells have multiple subsets, promoting or inhibiting the process of inflammation, coordinating multiple aspects of adaptive immunity (53). Under inflammatory stimulation, MSCs can secret EVs with activated TGF- $\beta$, which can inhibit $\mathrm{T}$ cell proliferation, especially CD4+ $\mathrm{T}$ cells through Smad and other pathways (54-57). MSC-EVs are rich in HLA-G5, which can inhibit the proliferation of CD4+ and CD8+ $\mathrm{T}$ cells and reduce the release of IFN- $\gamma$ (58). Matrix metallopeptidase derived from MSC-EVs cuts IL-2 receptor $\alpha$ (CD25) on the surface of activated T cells, thereby downregulating IL-2 signaling and inhibiting $\mathrm{T}$ cell proliferation (59). Additionally, MSCs-EVs may promote the differentiation of naive $\mathrm{T}$ lymphocytes into cells with anti-inflammatory phenotypes, such as Tregs (60-62). TGF- $\beta$ from MSC-EVs was also involved in the promotion of Treg proliferation $(63,64)$. Zhang et al. demonstrated that antigen-presenting cells (APCs) mediate the enhancement of Treg differentiation in vitro and in vivo by MSC-EVs $(31,65)$. In addition, MSC-EVs reduced pathogenic Th17 amplification and secretion of proinflammatory factors such as IL-17A, IL-21, IL-22, and IL-2 $(66,67)$. Regulatory B cells (Bregs) are subtypes of B cells that suppress immune responses, such as reducing pathogenic $\mathrm{T}$ helper cells (TH17 and TH1 cells), while promoting Treg cell proliferation (68). MSC-EVs increase the number of Bregs and promote IL-10 secretion $(60,69)$. In addition, MSC-EVs can directly inhibit the proliferation and activation of $\mathrm{B}$ cells $(9,70,71)$.

\section{Liver Immunity}

To clarify the immunomodulatory effects of MSC-EVs in liver diseases and explore other potential mechanisms, the immune environment of the liver should be determined. The liver is the central organ of metabolism and immune modulation. Most of the blood entering the liver comes from the portal vein rather than the hepatic artery. Blood enters the liver parenchyma mainly through the peripheral vessels of the portal vein, and then leaves the parenchyma via the central hepatic vein through the sinusoidal network (72). Hepatic sinuses are anatomic sites that regulate 


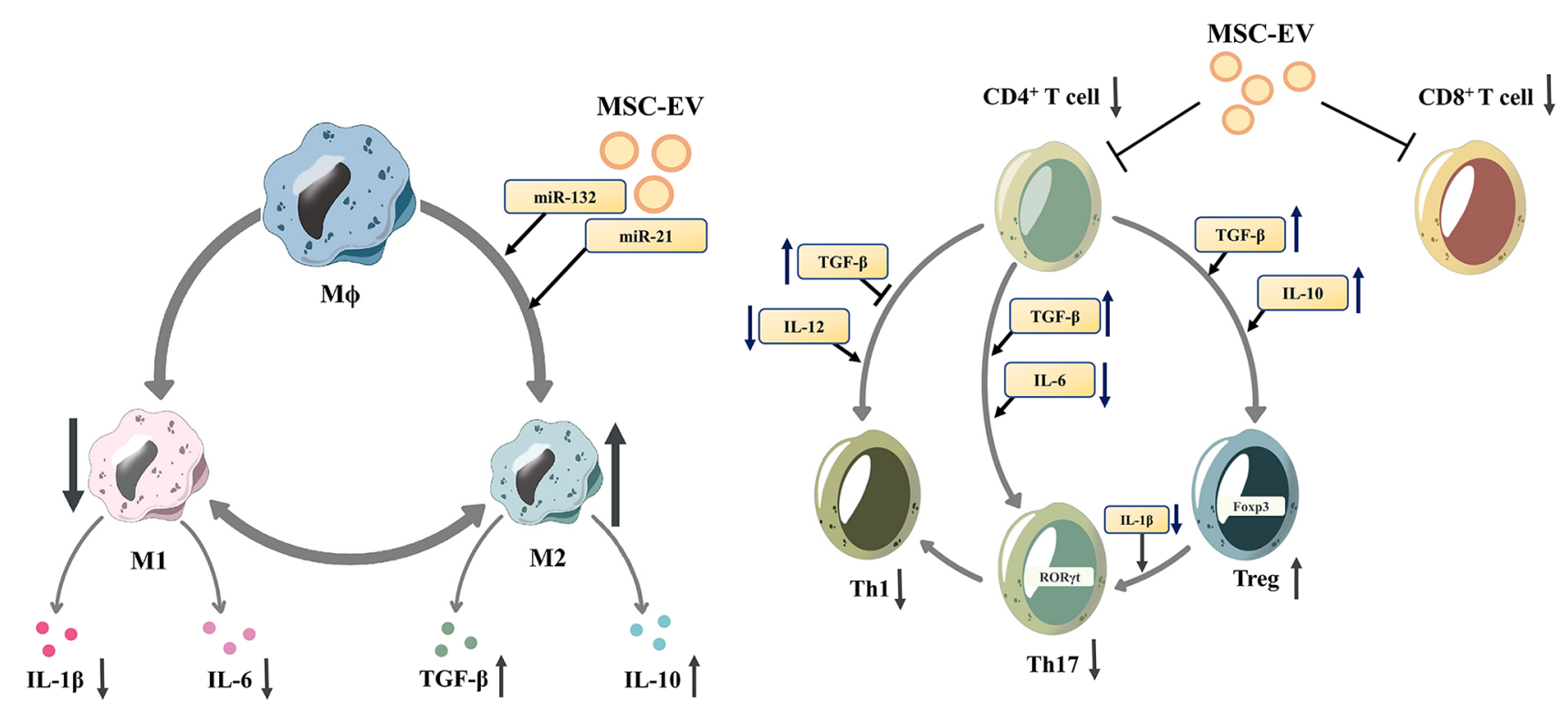

FIGURE 1 | Mesenchymal stem cell-derived extracellular vesicles modulate the differentiation of macrophages and T cells. Mesenchymal stem cell-derived extracellular vesicles (MSC-EVs)reduce the proliferation of proinflammatory cells (M1 macrophages, CD8+ T cells, Th1 and Th17 cells)and downregulate the release of IL-1 $\beta$ and IL-6. In contrast, MSC-EVs increase the proportion of anti-inflammatory subtypes (M2 macrophages and Tregs), and upregulate the release of antiinflammatory cytokines, such as TGF- $\beta$ and IL-10. M1 macrophage, M1-polarized phenotype macrophage; M2 macrophage, M2-polarized phenotype macrophage; Th 1 cells, T helper 1 cells; Th17 cells, T helper 17 cells; Tregs, regulatory T cells; IL-1 $\beta$, Interleukin $1 \beta$; IL-6, Interleukin 6; TGF- $\beta$, transforming growth factor- $\beta$; IL-10, Interleukin 10 .

immune homeostasis in the liver. The blood flow is slow in the hepatic sinuses, which prolongs the contact between lymphocytes and antigen-presenting cells and promotes lymphocyte exosmosis. In addition to parenchymal cells (hepatocytes and cholangiocytes), there are also nonparenchymal cells [such as hepatic stellate cells (HSCs) and hepatic sinusoidal endothelial cells (LSECs)] and a large number of immune cells (such as $\mathrm{T}$ cells, macrophages, dendritic cells, etc.) in the liver.

The liver innate immune system is modulated by multiple cellular components; Kupffer cells(KCs), DCs, NKs, NKTs and LSECs. During liver injury or infection, KCs phagocytize the pathogenic materials and release a large number of cytokines and other products to initiate acute inflammation with the rise in acute-phase proteins (APPs). APPs include C-reactive protein (CRP), serum amyloid A (SAA), complement components and others, and they play an important role in the innate immune response with their haemostatic, microbicidal and phagocytic functions (73). KCs are resident macrophages in the liver that can bind and trap pathogens in hepatic sinuses, accounting for $80-90 \%$ of tissue macrophages (74). When stimulated and activated, KCs can regulate the phenotype of their own and other immune cells. DCs are also important in innate immune response. There are four major subsets of DCs in the liver, including myeloid CD8a (-) B220 (-), lymphoid CD8a (+) B220 $(-)$, plasmacytoid CD8a (-) B220(+), and natural killer dendritic cells with a CD8a (-) B220 (-) NK1.1(+) phenotype (75). Both myeloid and plasmacytoid subsets can initiate innate immune responses. KCs and DCs are the first to detect pathogens and can recruit other immune cells such as monocytes and neutrophils into the liver (74). NK cells are important effectors of the innate immune system with their functions of lysing target cells and producing large quantity of cytolytic granules in the absence of prior antigen sensitization. NK cells in human blood can be divided into two subsets, CD56bright and CD56dim, and CD56dim is more in circulation. In contrast, the human liver is enriched in CD56bright NK cells that localize within hepatic sinusoids (76). During liver inflammation, NK cells are recruited early by chemokines expressed from KCs or LSECs, then secrete cytokines such as IFN- $\gamma$, promoting the progress of inflammation, or directly killing target cells such as virusinfected hepatocytes or hepatocellular carcinoma (77). Natural killer T (NKT) cells are enriched in the liver and are divided into two main subsets (type I or invariant NKT cells and type II or diverse NKT cells). Type I NKT cells are more prevalent in murine liver and Type II NKT cells are more abundant in human liver (78). NKT cells are capable of recognizing lipid antigens presented by CD1d, then release Th1 (IFN- $\gamma$, TNF- $\alpha$ ), Th2 (IL-4, IL-5, IL-10) or Th17 (IL-17, IL-22) cytokines activating other innate immune cells and adaptive T cells (79). Type I NKT cells mainly show a proinflammatory effect in liver injury (78). In contrast, type II NKT cells were able to inhibit the proinflammatory response induced by type I NKT cells, thus preventing liver injury. LSECs are the most common nonparenchymal cells in the liver and form the vascular wall of 
sinusoidal cortex with open fenestrae and lack of a basement membrane. Unlike other endothelial cells, LSECs highly express scavenger receptors and mannose receptors, giving them a strong endocytosis ability. Accordingly, LSECs can directly ingest hepatitis viruses such as $\operatorname{HBV}$ and $\operatorname{HCV}(80,81)$.

Adaptive immunity has a crucial role in controlling liver inflammation. Naive T cells are primed by APCs, such as KCs and DCs, then proliferate and differentiate into effector cells. T cells are divided into CD4 T cells, CD8 T cells and $\gamma \delta$-T cells according to their phenotypes and functions. CD4 T cells can be divided into proinflammatory subgroups such as Th1、Th2、 Th17 and follicular helper T (Tfh) cells $(82,83)$, and Tregs, which usually suppress the inflammation (84). CD8 T cells include cytotoxic $\mathrm{T}$ cells (Tc), the main cell killer in adaptive immunity, and CD8 Treg cells, which suppress immune responses (85). The functions of $\gamma \delta$-T cells are phagocytosis and tumor killing, but also immune regulation (86).

Blood in the portal vein is full of nutrients and accompanying antigens from the gastrointestinal tract. Therefore, immune tolerance is required for the hepatic immune system. Hepatic APCs are core to the immune tolerance of the liver by their capacity of suppressing adaptive immunity. Under steady-state conditions, myeloid DCs, and plasmacytoid DCs produce massive anti-inflammatory cytokines such as IL-10 and TGF$\beta$, inducing Tregs and tolerogenic T-cell responses in the liver (87). KCs also play a pivotal role in liver immune tolerance. KCs can inhibit $\mathrm{T}$ cell activation by secreting prostaglandins such as Prostaglandin E2 (PGE2)and 15deoxy- $\Delta 12$, 14-prostaglandin J2 (15d-PGJ2) (88), while this inhibition can be reversed by pathogen-related molecules (such as TLR3) or inflammatory cytokines (89).

Moreover, liver immune regulation was also associated with damage-associated molecular patterns (DAMPs) such as high mobility group protein 1 (HMGB1) and IL33 $(90,91)$, NOD-like receptor family, pyrin domain containing 3(NLRP3) (92), TLRs (TLR3, TLR4, TLR7, TLR9) (93) and complements (94).

In general, there is immune tolerance in the liver to prevent unwanted inflammatory responses. However, when the level or context of antigens changes, the liver can switch from immune hyporesponsiveness rapidly to an active state of generating inflammatory responses. This immune regulation involves the functional diversity of macrophages and dendritic cells, the ratio of different types of $\mathrm{T}$ cell subsets (such as Th17 and Treg), the balance between pro-inflammatory and anti-inflammatory cytokines, and other immune-related factors.

\section{Therapeutic Application of MSC-Derived EVs in Liver Diseases}

In this section, we have summarized the preclinical studies of MSC-EVs as a cell-free therapy in liver diseases, including NAFLD, autoimmune hepatitis (AIH), acute liver failure, liver fibrosis and hepatic ischemia-reperfusion injury, focusing on the immunomodulatory effects of MSC-EVs (Table 1, Figure 2).

\section{Non-Alcoholic Fatty Liver Disease}

Non-alcoholic fatty liver disease (NAFLD) is a continuum of liver abnormalities ranging from nonalcoholic fatty liver disease (NAFL) to nonalcoholic steatohepatitis (NASH). At present, NAFLD is a critical issue of liver diseases, and its incidence has increased globally, reaching $24 \%$ in the latest statistics (102), posing a significant economic burden (103). NAFLD is closely related to chronic inflammation caused by stimuli both inside and outside the liver, and this inflammation is closely associated with macrophages and neutrophils (104). KCs secrete TNF, CCL2, and CCL5 to mediate monocyte infiltration, promoting steatosis and subsequent fibrosis progression (105). In addition, toxic lipids stored in KCs participate in the early stage of inflammation (106). Neutrophils seem to be observed in most liver inflammation. Focusing on NAFLD, the proinflammatory effects were based on myeloperoxidase (MPO) (107). In contrast, DCs play a protective role in NAFLD (108). NAFLD has a high incidence but limited treatments, mainly depending on body weight loss. Currently, there are many drugs targeting NAFLD in clinical trials, such as the farnesoid $\mathrm{X}$ receptor (FXR) agonist obeticholic acid; however, none of them have shown certain therapeutic effects (109). Thus, some researchers began to pay attention to other potential treatments.

Abrogation of liver inflammation might be achieved by MSCEV treatment. At present, many studies have reported that mesenchymal stem cell-derived exosomes can improve liver inflammation, reduce alanine aminotransferase (ALT) and aspartate aminotransferase (AST) levels, and alleviate liver fibrosis in vivo $(95,110,111)$. Recent studies have shown that the immunotherapeutic effect of MSC-EVs on NAFLD mainly depends on macrophages. LPS promotes the process of inflammation in NASH by activating KCs through the TLR4 signaling pathway (112). However, MSC-EVs prevented this promotion, especially the activation of M1 macrophages, and downregulated the expression of inflammatory cytokines, such as TNF-A, IL-1 $\beta$ and IL-6 in NASH models. In the LPS/TLR4 pathway, myeloid differential protein (MyD) 88 is activated,

TABLE 1 | The role of MSC-EVs in the modulation of liver immunity in various liver diseases.

\begin{tabular}{|c|c|c|c|c|}
\hline Type of disease & Immune Cell & Pathway & Effects & Reference \\
\hline $\mathrm{NASH}$ & Macrophage & STAT3-ARG-1 & polarizing M2 macrophages and producing related ARG-1 and IL-10 & (95) \\
\hline $\mathrm{AlH}$ & Macrophage & miR-223-3p-STAT3-IL-1 $\beta, I L-6$ & reducing Treg/Th17 ratio & (96) \\
\hline Acute liver failure & Macrophage & miR-17-TXNIP/NLRP3 & reducing NLRP3 inflammasome activation & $(97)$ \\
\hline Acute liver failure & Macrophage & miR-299-3p-TGN-NLRP3 & reducing NLRP3 inflammasome activation & (98) \\
\hline Acute liver failure & Macrophage & miR-455-3p-PIK3r1 & blocking the activation of the IL- 6 signaling pathway & (99) \\
\hline Liver Fibrosis & Macrophage & LPS/TLR4-NF- $\kappa B$ & downregulating the expression of TNF- $\alpha, I L-1 \beta$ and IL- 6 & (95) \\
\hline$|\mathrm{R}|$ & $\mathrm{CD} 4+\mathrm{T}$ & CCT2-Ca2+-calcineurin--NFAT1 & downregulating CD154 expression & $(100)$ \\
\hline$|R|$ & $\mathrm{CD} 4+\mathrm{T}$ & miR-1246-IL-6-gp130-STAT3 & enhancing the shift of Th17 toward Treg cells & $(101)$ \\
\hline
\end{tabular}




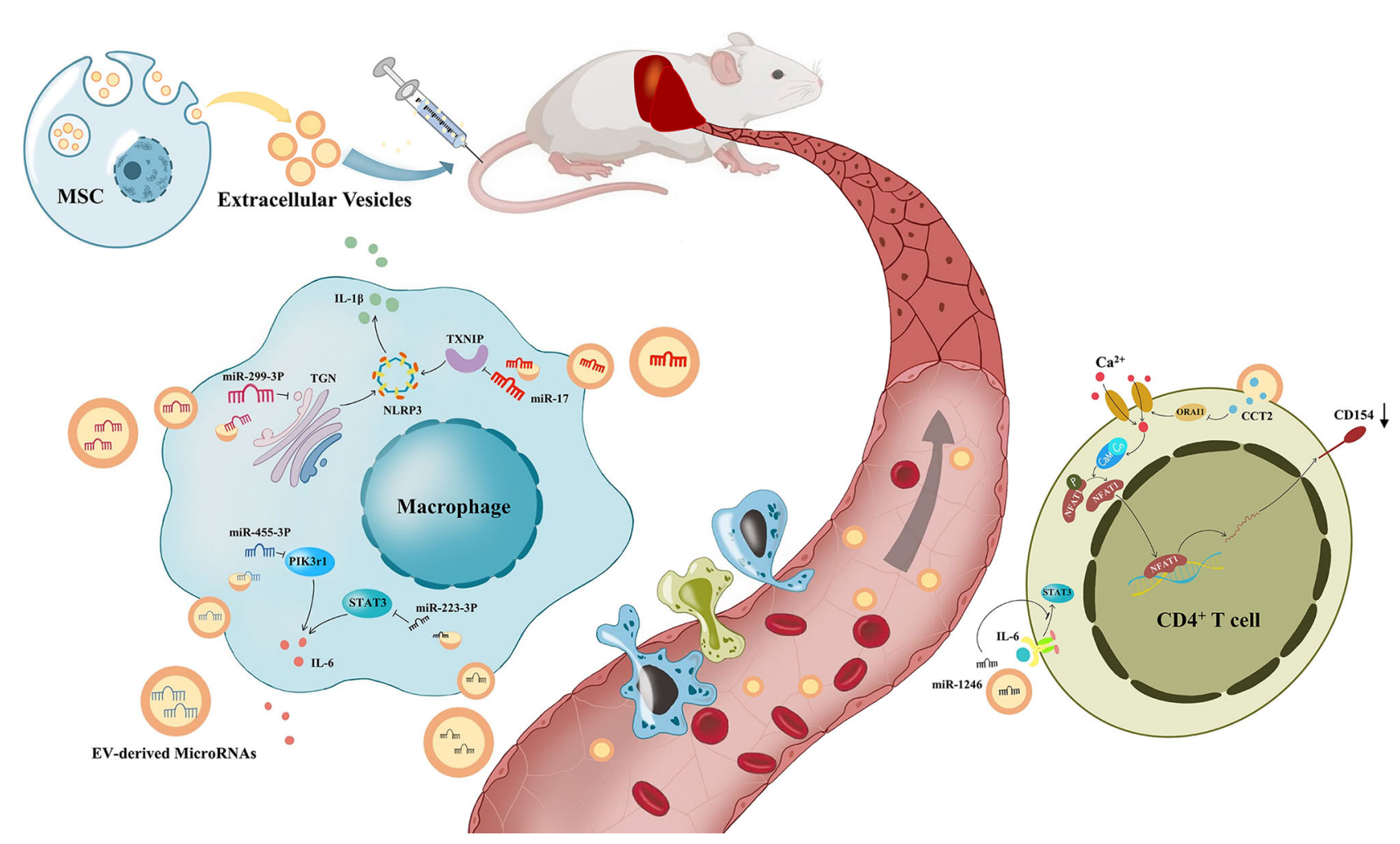

FIGURE 2 | The process of immune regulation by mesenchymal stem cell-derived extracellular vesicles on the liver. Under the modulation of Mesenchymal stem cell-derived extracellular vesicles(MSV-EVs), macrophages reduce the release of IL-6 and IL-1 $\beta$, and CD4+ T cells reduce the expression of CD154. Liver inflammation was improved by the immune modulation of MSC-EVs, which alleviates different kinds of liver diseases.

leading to TNF receptor associated factor 6(TRAF6) activation and phosphorylation of $\mathrm{p} 65$ and $\mathrm{I} \kappa \mathrm{B}-\alpha$, allowing $\mathrm{NF}-\kappa \mathrm{B}$ to translocate to the nucleus. MSC-EVs could suppress the phosphorylation of $\mathrm{p} 65$ and $\mathrm{I} \kappa \mathrm{B}-\alpha$, and the transcriptional activity of $N F-\kappa B$, but they did not suppress the NF- $\kappa B$ transcriptional activity induced by overexpression of TRAF6 in HEK293 cells. These results reveal that MSC-EVs may inhibit the early steps of the LPS/TLR4 signaling pathway (110). In addition, MSC-EVs increased the number of CD11b + F4/80 + Ly6c low anti-inflammatory macrophages in the liver of mice with NASH (111). F4/80+ macrophages have relatively high phagocytosis activity and therefore actively participate in the elimination of dead white blood cells, pathogens and cell debris, promoting the regression of inflammation (113). MSC-EVs contain p-STAT3, which can bind to STAT3 target DNA and promote the transcriptional activation of the ARG-1 promoter/enhancer, thereby polarizing M2 macrophages and producing related ARG-1 and IL-10 (95).

In addition to regulating immune homeostasis, MSC-EVs can also regulate the metabolic homeostasis of NASH (95) and the apoptosis and autophagy of hepatocytes. El-Derany and colleagues demonstrated that MSC-EVs reduce apoptosis of hepatocytes, but activate mitochondrial autophagy by upregulating miRNA-96-5p expression and downregulating caspase-2 expression in HFD-induced NASH (114). He et al. showed that MSC-EVs promoted autophagy via the AMP-activated protein kinase (AMPK) pathway in L-O2 cells, resulting in the improvement of glucose and lipid metabolism (115).

\section{Autoimmune Hepatitis}

Autoimmune hepatitis (AIH) is a progressive autoimmune liver disease that is characterized by liver inflammation, circulating autoantibodies and hypergammaglobulinemia (116). Clinically, the diagnosis of AIH mainly depends on liver biopsy by observing interface hepatitis, rosettes, and lymphocyte invasion. The current first-line therapy is standard immunosuppressive treatment using corticosteroids with or without azathioprine (117). Without effective controls of inflammation, AIH may result in rapid progression to liver fibrosis, cirrhosis, and even hepatocellular carcinoma. The pathogenesis of $\mathrm{AIH}$ involves molecular mimicry, immune activation and loss of immune tolerance (118). CD4+T cells appear central to AIH immune mechanisms. When immune responses to external pathogens occur, recognition of autoantigens with similar structures also occurs through 
molecular mimicry, such as cytochrome P450 2D6 (CYP2D6) (119). Consequently, these autoantigens will be processed and presented to uncommitted naive CD4+ T helper (Th0) cells through abundant APCs in the liver, such as DCs, macrophages, and B cells. Stimulated by various cytokines, Th0 cells differentiate into Th1, Th2 and Th17 cells and then produce a large amount of proinflammatory factors. Through these processes, $\mathrm{T}$ cells promote the occurrence and persistence of liver inflammation. Tregs are quantitatively impaired in $\mathrm{AIH}$, and this impairment is more pronounced during active disease (120). This imbalance in the number and function of Tregs and T effector cells leads to the loss of immune tolerance, which eventually results in AIH.

MSC-EVs are capable of promoting liver immune homeostasis and relieving liver inflammation by reversing the decline in Tregs in AIH. Tamura et al. reported that the necrotic area of the liver was significantly reduced and ALT elevation was inhibited in mice with Concanavalin A (ConA)-induced AIH. In addition, MSC-EVs significantly decreased the expression of the proinflammatory cytokine IL-2, while enhancing the mRNA expression of anti-inflammatory cytokines, such as TGF- $\beta$ and hepatocyte growth factor (HGF), and this effect was correlated with the amount of MSC-EVs injected. Moreover, the number of Tregs was increased. They speculated that KCs produced cytokines such as TGF- $\beta$ after engulfing MSC-EVs and then promoted the production of Tregs, thus inhibiting liver inflammation caused by ConA (121). Lu and colleagues also discovered that liver inflammation, ALT and AST levels were significantly decreased in mice with ConA-induced AIH after MSC-EV treatment. However, they did not observe an increase in the number of Treg cells, and they found that the ratio of Treg/ Th17 cells increased instead. They reported that miR-223-3p in MSC-EVs could reduce the LPS-induced elevation of the inflammation-related genes STAT3 and p-STAT3 in macrophages, which is an important upstream activator of IL$1 \beta$ and IL-6. STAT3 is known to activate RORt and promote IL17 secretion by Th17 cells, IL- $1 \beta$ converts Treg cells into Th17 cells, and IL- 6 can promote the differentiation of naive T cells into Th17 cells. Therefore, the proportion of Tregs/Th17 cells increased after MSC-EV treatment, which alleviated AIH (96). Moreover, miR-223 in MSC-EVs was demonstrated to attenuate NLRP3 and Caspase-1 levels in AML cells, thus reducing pyroptosis of hepatocytes (122).

\section{Acute Liver Failure}

Acute liver failure (ALF) is defined as a syndrome of severe injury to liver cells that leads to altered coagulation and mentation without the basis of chronic liver disease (123). Viral hepatitis, drug-induced liver injury, alcohol consumption and autoimmunity are the main causes of acute liver failure. Its clinical manifestations include hepatic encephalopathy, jaundice, coagulation dysfunction, and so on. Due to the amelioration of liver transplantation and intensive care, outcomes for patients with acute liver failure have improved, however, more effective treatments are needed despite liver transplantation.
ALF is closely related to macrophages (10). DAMPs released from dead cells can bind to pattern recognition receptors on macrophages, subsequently inducing the production of cytokines and chemokines and then activating inflammasomes, such as NLRP3, leading to the recruitment of neutrophils and mononuclear derived macrophages into the liver, which is demonstrated in the process of ALF (124). On the other hand, KCs release IL-10 and remove apoptotic materials for protection (125). Numerous studies have shown that MSC-EVs can inhibit the proliferation and activation of proinflammatory macrophages, subsequently reducing the secretion of cytokines such as IL-1 $\beta$, IL-6, IL-18, and TNF- $\alpha$ and therefore significantly improving ALF $(97-99,126,127)$. Researchers proved that the mechanism could be related to the inhibition of the NLRP3 pathway by MSC-EVs $(97,98,126)$. In addition, MSC-EVs have shown their effectiveness in reducing apoptosis of hepatocytes, which is regarded as an important pathological manifestation of early-stage ALF (128-131). Some researchers believe that the reduction in apoptosis results from the activation of autophagy in hepatocytes through MSC-EVs (128). Others believe that MSC-EVs attenuate apoptosis due to the alleviation of hepatic oxidant injury $(129,130)$. Moreover, MSC-EVs play an important role in promoting hepatic regeneration. MSC-EVs can induce the conversion of hepatocytes into hepatic oval cells, which have the ability to proliferate in large quantities (132). Tan et al. discovered that the expression of proliferation proteins (PCNA and cyclin D1) was higher in the MSC-EV-treated group, which suggests that MSC-EVs upregulate the priming-phase genes of hepatocytes (131). Damania et al. proved that the ratio of residual liver to estimated liver weight was increased through MSC-EVs in both partial hepatectomy and ischemiareperfusion injury-induced liver failure mouse models (133).

\section{Liver Fibrosis}

Most chronic liver diseases, such as viral liver disease, NAFLD, and alcoholic liver disease, can progress to fibrosis. Liver fibrosis is the replacement of damaged normal tissue by fibrous scarring resulting from the accumulation of extracellular matrix (ECM) proteins (mainly cross-linked collagen type I and type III) (134). Myofibroblasts are the main source of ECM in liver fibrosis, and hepatic stellate cells (HSCs) and portal vein fibroblasts can be transformed into myofibroblasts. HSCs can be activated in response to injury, upregulate the expression of $\alpha$-smooth muscle actin( $\alpha$-SMA), secrete collagen type I, migrate to the site of injury, and secrete ECM to produce fibrous scars. $\beta$ catenin and cytokines such as TGF- $\beta$ can effectively stimulate the activation of HSCs and promote the transcription of collagen type I $(135,136)$. Macrophages play dual roles in liver fibrosis. On the one hand, they can produce cytokines and chemokines such as TGF- $\beta$ to activate HSCs and enhance liver fibrosis. On the other hand, they can attenuate liver fibrosis by antiinflammation and secretion of matrix metalloproteinases (MMPs), such as Mmp9 and Mmp12, to degrade and phagocytose existing ECM (137). It is widely believed that M1type macrophages can develop liver fibrosis by promoting the 
propagation of inflammation, while M2-type macrophages attenuate fibrosis by promoting cell proliferation and reducing apoptosis of hepatocytes. However, recent studies have found that M1-type macrophages may also be involved in the process of fibrosis regression (138).

Recently, numerous preclinical studies have demonstrated the antifibrotic effect of MSC-EVs in the lung (139), liver (140), kidney (141), and heart (142). Focusing on liver fibrosis, MSCEVs promote liver tissue repair by reducing inflammation, therefore alleviating fibrosis. MSC-EVs upregulated the expression of MMPs (143), such as MMP9 and MMP13, and anti-inflammatory factors, such as TGF- $\beta 1$ and IL-10 $(140,143)$, downregulated the expression of pro-inflammatory factors such as TNF- $\alpha$, IL- $1 \beta$ and IL- 6 , and TGF- $\beta$ (110). In addition, MSCEVs can improve CCL4-induced liver fibrosis by inhibiting epithelial-to-mesenchymal transition (144). Moreover, MSCEVs were shown to inhibit HSC activation. Rong et al. reported that MSC-EVs can inhibit the activation of HSCs through the $\mathrm{Wnt} / \beta$-catenin pathway in vivo and in vitro (145). Kim et al. demonstrated that miR-486-5p derived from MSC-EVs directly binds to the 3' untranslated region (UTR) of SMO mRNA and inhibits its expression, resulting in the inactivation of HSCs (146). Wu et al. showed that miR-150-5p was poorly expressed and CXCL1 was highly expressed in liver fibrosis, while MSC-EVs could transfer miR-150-5p to HSCs, subsequently inhibiting the activation of HSCs by downregulating CXCL1 expression (147).

\section{Ischemia-Reperfusion Injury}

Ischemia-reperfusion injury (IRI), including ischemic organ injury and inflammation-mediated reperfusion injury, is an important cause of liver injury in surgical procedures including hepatectomy and liver transplantation. Many factors are involved in the process of IRI, such as the inflammatory response, reactive oxygen species (ROS), apoptosis, and autophagy (148). The immune response to IRI includes the activation of KCs, DCs, NK cells, and T cells, as well as the involvement of various cytokines and inflammasomes $(149,150)$.

Zheng et al. found that CCT2 in MSC-EVs downregulated the expression of CD154 on CD4+ T cells in the liver through the restrictive Ca2+ - calcineurin - NFAT1 pathway (100). The interaction of CD154 and CD40 stimulated innate and adaptive immune responses, and it has been proven that CD154 on CD4+ T cells plays a pivotal role in liver IRI (151). Therefore, MSC-EVs alleviate liver ischemia/reperfusion injury. miR-1246 derived from MSC-EVs could bind GSK3 $\beta$ in hepatocytes, significantly inhibit the expression of Wnt1, Wnt3a and $\beta$-catenin, activate the $\mathrm{Wnt} / \beta$ catenin signaling pathway, and reduce the IRI induced production of TNF- $\alpha$, IL- 6 , and IL- $1 \beta$, thereby improving IRI by reducing inflammation (152). In addition, miR-1246 in MSCEVs further upregulated TGF- $\beta 1$ and IL-10, and downregulated IL-6 and IL-17 (101). TGF- $\beta$ alone induces the differentiation of naive $\mathrm{CD} 4+\mathrm{T}$ cells into Treg cells, whereas it induces differentiation into Th17 cells in collaboration with IL-6, which is controlled by the IL-6-gp130-STAT3 signaling pathway. As a result, miR-1246 improves liver IRI by regulating the balance between proinflammatory Th17 cells and anti-inflammatory Treg cells. In addition, hepatic infiltration of macrophages and neutrophils could be significantly reduced by treatment with MSC-EVs (153). Moreover, the role of MSC-EVs in apoptosis and autophagy has also been considered. In contrast, Bo et al. suggested that the reduction in apoptosis through MSC-EVs was based on the enhancement of autophagy (154).

\section{THERAPEUTIC ADVANTAGES OF MSC- EVS OVER MSCS AND THE ROLE OF MSC-EVS AS DRUG-DELIVERY VESICLES}

The studies above suggest the immunomodulatory effects of MSC-EVs in various liver diseases, and in this section, we will discuss the advantages of MSC-EVs over MSCs in applications of clinical therapies and the applications of MSC-EVs as drugdelivery vesicles.

Compared to MSCs, which would be trapped in the pulmonary capillary network when administered intravenously $(155,156)$, leading potential pulmonary embolism (157), EVs are much smaller and can even pass-through blood-brain barriers (BBB) (158), reducing the loss of therapeutic material and the risk of treatment. Second, the cell viability of MSCs will decrease in cryogenic storage during transport. However, EVs can remain biologically active for 24 hours at $4^{\circ} \mathrm{C}(159)$ and for at least 7 14 days at $-80^{\circ} \mathrm{C}(160,161)$. Furthermore, MSC treatment requires hundreds of millions of cells, which usually takes approximately 10 weeks in cell culture, bringing a high cost of time and money (162). Comparatively, EVs can be acquired continuously and efficiently in large quantities through $3 \mathrm{D}$ culture systems and other methods (162). Moreover, there may be a risk of tumorigenesis after administration of MSCs, which does not occur in EVs (163). However, there is no reported clinical evidence of MSC-induced tumors due to the inefficiency of MSC transformation in vivo. Therefore, MSC-EVs are more feasible and appealing than MSCs as a clinical treatment in the future.

The low immunogenicity of EVs make them ideal natural vesicles compared with synthetic vesicles (164). EVs also have many advantages over other natural vesicles. First, intrinsic proteins and genetic materials in EVs indicate that EVs are capable of loading similar but exogenic biomaterials effectively. In addition, EVs are distributed widely in biological fluids such as blood, urine, and breast milk, which shows their good tolerance in the human body. Moreover, EVs can transport their cargo to target cells across the plasma membrane (165). Most importantly, EVs have the ability to target, which can be enhanced by membrane modification (166). MSCs have become an ideal source of exosomes due to their immunosuppressive effects and the ability to produce exosomes efficiently in large quantities (167). MSC-EVs are widely applied as therapeutic vehicles in liver diseases. In studies of liver fibrosis, MSC-EVs were used to carry various RNAs and proved to have antifibrotic effects, reduce ECM deposition, and improve liver function. 


\section{Clinical trials \\ Design}

\section{Type of cells, dose, and}

Human mesenchymal stem cell transfusion is safe and improves liver function in acute-onchronic liver failure patients (11)

An open-labeled,
parallel-controlled,
phase I/II trial

Mesenchymal stem cell therapy in decompensated liver cirrhosis: a long-term

follow-up analysis of the randomized controlled clinical trial (194)

Bone Marrow Mesenchymal Stem Cells in Acute-on-Chronic Liver Failure Grades 2 and 3 : A Phase I-II Randomized Clinical Trial (195)

\section{placebo-controlled,}

Phases I and II, randomized clinical trial

Transplantation with GXHPC1 for Liver Cirrhosis: A single-center, Phase 1 Trial (196)

open-labeled study

Improvement of liver function in liver cirrhosis A phase I-II clinical patients after autologous mesenchymal stem cell trial injection: a phase I-II clinical trial (197)

Effects of allogeneic mesenchymal stem cell transplantation in the treatment of liver cirrhosis caused by autoimmune diseases (198)

A single-center, open-labeled study

A prospective, open- -Allogenic UC-MSCs

Human umbilical cord mesenchymal stem cells A single-center, improve liver function and ascites in decompensated liver cirrhosis patients (199)

Allogeneic bone marrow-derived mesenchymal stromal cells for hepatitis B virus-related acuteon-chronic liver failure: A randomized controlled trial (200) open-labeled study

Allogenic UC-MSCs $-0.5 \times 10^{6}$ UC-MSCs per kilogram - IV

A prospective, open- -Allogenic BM-MSCs label, nonblinded randomized clinical trial

$-1 \sim 10 \times 10^{5}$ BM-MSCS per kilogram delivery route Allogenic UC-MSCs $-0.5 \times 10^{6}$ UC-MSCs per kilogram

$-0.5 \times 10^{6}$ UC-MSCs per kilogram

- IV

-Allogenic BM-MSCs

$-1.0 \times 10^{6}$ UC-MSCs per kilogram

- IV

-Autologous AD-MSCs

$-1.0 \times 10^{8}$ AD-MSCs/ participants

-Intrahepatic Injection

-Autologous BM-MSCs

$-3.0 \sim 5.0 \times 10^{7} \mathrm{BM}-$ MSCs/participants - IV MSCs/CB-MSCs

$-1.0 \times 10^{6}$ MSCs per kilogram

- IV

participants

43 ACLF patients

MSC-treated group $(n=24)$

-Control $(n=19)$

-219 patients with HBV-related decompensated liver cirrhosis

-UC-MSC-treated group $(n=108)$ -Control $(n=111)$

-9 cirrhotic patients

BM-MSC treated group $(n=4)$

-Control $(n=5)$

-6 cirrhotic patients

-8 patients [hepatitis $B(n=4)$, hepatitis $C$

$(\mathrm{n}=1)$, alcoholic $(\mathrm{n}=1)$, with end-stage liver disease having Model for

End-Stage Liver Disease score

$\geq 10$

\section{autoimmun}

Diseases

- UC-MSC treated group $(n=23)$

-BM-MSC treated group $(n=1)$

-CB-MSC treated group $(n=2)$

-45 patients with HBV-related decompensated 12 liver cirrhosis

-UC-MSC-treated group $(\mathrm{n}=30)$

-Control $(n=15)$

-110 patients with HBV-related ACLF $-I V$

BM-MSC treated group $(n=56)$ -Control $(n=54)$
Follow-

Results

2 -Safety of UC-MSC transfusion

months in ACLF patients;

-UC-MSC transfusions reduced the MELD score, improved liver function and alleviated liver damage for ACLF Patients

13 75 -No significant side effects or treatment-related

months complications were observed in the UC-MSC group

UC-MSC treatment markedly improved liver function

90 days - BM-MSC infusion was safe, without significant side effects

BM-MSC treatment improved liver function months

Administration of AD-MSCs can be considered safe for patients with liver cirrhosis.

- AD-MSC treatment improved liver function, METAVIR scores, Child-Pugh scores, MELD score and the quality of life of the cirrhotic patients

-Treatment was well tolerated by all patients

months - BM-MSC treatment improved liver function months

-Allogeneic MSC treatment through the peripheral vein probably was safe

Allogeneic MSC treatment improved liver function

-UC-MSC transfusion was clinically safe

months - UC-MSC treatment improved liver function and reduced the volume of ascites 
Transplantation with autologous bone marrowderived mesenchymal stem cells for alcoholic cirrhosis: Phase 2 trial (12)

Randomized trial of autologous bone marrow mesenchymal stem cells transplantation for hepatitis B virus cirrhosis: regulation of Treg/ Th17 cells (201)

Peripheral vein infusion of autologous mesenchymal stem cells in Egyptian HCV-

positive patients with end-stage liver disease (202)

Phase II trial: undifferentiated versus differentiated autologous mesenchymal stem cells transplantation in Egyptian patients with HCV induced liver cirrhosis (203)

Autologous bone marrow-derived cell transplantation in decompensated alcoholic liver randomized stud disease: what is the impact on liver histology and gene expression patterns? (204)

Randomized placebo-controlled trial of mesenchymal stem cell transplantation in decompensated cirrhosis (205)

Allogeneic bone marrow mesenchymal stem cell transplantation in patients with UDCA-resistan primary biliary cirrhosis (206) mesenchymal stem cell transfusion in patients with primary biliary cirrhosis (207)

A multicenter, label, phase II tria label, clinical trial

A prospective, randomized study

A randomized,

A single-center, labeled study randomized, open-

-Autologous BM-MSCs $-5.0 \times 10^{7}$ BM-MSCs/ participants

-hepatic arterial injection

A randomized, open- - Autologous BM-MSCs

$-0.75 \pm 0.50 \times 10^{6} \mathrm{BM}$ MSCs/participants

-hepatic arterial injection -Autologous BM-MSCs

$-1.0 \times 10^{6}$ BM-MSCs per kilogram $-\mathrm{IV}$

A randomized, phase -Autologous BM-MSCs II clinical trial (Undifferentiated and

differentiated

differentiated respectively)

$-1.0 \times 10^{6}$ BM-MSCs per kilogram

- IV

-Autologous BM-MSCs

$-0.47 \pm 0.15 \times 10^{8} \mathrm{BM}-$

MSCs per kilogram

- hepatic arterial injection

-Autologous BM-MSCs

placebo-controlled

A median of 195 million (range: 120-295 million) BM-MSCs per kilogram

- IV open-labeled study

Allogenic BM-MSCs

-10 patients with ursodeoxycholic acid (UDCA)- 12 A median of 195 million resistant primary biliary cirrhosis (PBC) (range: 120-295

million) BM-MSCs per

kilogram

- hepatic arterial injection

A single-arm, open-

-55 patients with alcoholic cirrhosis

-18 in the control group

-18 in the one-time autologous BM-MSC group

-19 in the two-time autologous BM-MSC group -56 patients with hepatitis $B$ virus cirrhosis

-BM-MSC treated group $(n=27)$

-Control $(n=29)$

-40 patients with post-HCV end-stage liver disease

-BM-MSC treated group $(n=20)$

-Control $(n=20)$

-

-undifferentiated

BM-MSC treated group $(n=9)$

-differentiated

BM-MSC treated group $(n=6)$

-Control $(n=10)$

-58 patients with decompensated alcoholic liver 3 disease

-BM-MSC treated group $(\mathrm{n}=28)$

-Control $(n=30)$

-27 patients with decompensated liver cirrhosis 12

-BM-MSC treated group $(n=28)$

-Control $(n=30)$

-Allogenic UC-MSCs

-7 PBC patients with a suboptimal response to

$-0.5 \times 10^{6}$ UC-MSCs per UDCA treatment kilogram

BM-MSC treatment increases the 24-week sunviva

rate by improving liver function and decreasing

the incidence of severe infections

12 Autologous BM-MSC transplantation safely improved

months histologic fibrosis and liver function in patients with

alcoholic cirrhosis

weeks

MSC transplantation further improved liver function

-BM-MSC treatment increased Treg cells and

decreased Th17 cells

$6 \quad-B M-M S C$ treatment through the peripheral vein was months safe

-BM-MSC treatment improved liver functions and ascites

$6 \quad$-BM-MSC treatment through the peripheral vein was months safe

-BM-MSC treatment improved liver functions and ascites

With the negative results from the clinical trial, the months impact of the BM-MSC treatment has to be interpreted as weak, and it is not able to modify the clinical course of this severe liver disease

-Autologous bone marrow MSC transplantation months through peripheral vein probably has no beneficial effect in cirrhotic patients

- No transplantation-related side effects were observed

BM-MSC treatment improved liver functions and the quality of life

-the percentage of CD8+ T cells was reduced, while that of $\mathrm{CD} 4+\mathrm{CD} 25+\mathrm{Foxp} 3+\mathrm{T}$ cells was increased in peripheral lymphocytic subsets. Serum levels of IL-10 were elevated

UC-MSC transfusion via a peripheral vein is safe

-UC-MSC treatment reduces the ALP and GGT levels, and improves clinical symptoms including fatigue and pruritus

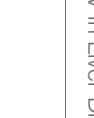


These exogenic RNAs include miR-181-5p (168), miR-122 (169), siRNA-STAT3 and mASO-STAT3 (170). Additionally, in AIH, MSC-EVs carrying dexamethasone (DEX) could target macrophages in the liver, therefore increasing the distribution of DEX in liver tissues and leading to DEX reduction in circulation. As a result, the anti-inflammatory therapeutic effect of DEX was enhanced while its side effects were reduced in mice with ConA-induced AIH (171).

\section{LIMITATIONS AND IMPROVEMENTS IN APPLICATIONS OF MSC-EVS}

Although MSC-EVs have shown great potential for immunomodulation and tissue regeneration, there are some limits in EV treatment that we should pay attention to.

Issues of heterogeneity and short half-life have hindered the application of EVs in clinical treatment. MSCs are derived from various tissue sources, resulting in different types of MSC-EVs. Although EVs from different types of MSCs exhibit similar morphology, phenotype, and function, proteomic system analysis indicates variability, which influences the therapeutic effects of MSC-EVs (172). Furthermore, recent studies have shown that the molecular composition of EVs is not cell-type dependent only but is also different in the same parental cell (173). This suggests that the molecular heterogeneity of EVs is the result of the subcellular origin of exosomes and donor cell activation status (174). However, ultracentrifugation, as the most commonly used strategy in the isolation of EVs, cannot categorize the properties of individual vesicles. To solve this problem, many improvements in EV isolation technology have emerged, such as fluorescent labeling and subsequent quantitative and qualitative analysis by high-resolution flow cytometry (175), the development of dedicated flow cytometry (176), and laser tweezers Raman spectroscopy (177). However, there is still no way to effectively eliminate this heterogeneity to meet the criteria in clinical therapy.

Another limitation is the short half-life of EVs (2 minutes to 30 minutes) (178-180) and quick clearance by the mononuclear phagocyte system (MPS) (181). Recent studies have focused on the local delivery of EVs through tissue engineering, which could be a potential strategy to enhance their feasibility. Hydrogels are polymeric networks with three-dimensional structures capable of absorbing large amounts of water or biological fluids (182). Hydrogels provide spatial and temporal control over the release of various therapeutic agents, including molecular drugs and cells (183). Due to the features of high tissue-like water content, easy implantation, and high biocompatibility, hydrogels have been increasingly used as carriers of EVs for tissue engineering. The strategy of using hydrogels as carriers for MSC-EVs has been widely used in bone (184), cartilage (185), skin (186), the nervous system (187), and the heart (188). Hydrogels showed good biocompatibility and excellent mechanical properties. Furthermore, hydrogels could release EVs continuously, enhance the stability of EVs, and improve therapeutic effects. Mardpour et al. applied tetra-PEG hydrogels 
to encapsulate MSC-EVs and then injected them upon intraperitoneal injection into TAA-induced chronic liver injury (CLI) mice. They reported that restricted EVs were sustained to be released over 4 weeks by gradual biodegradation and swelling of hydrogels. Conversely, free-EVs in controls were eliminated from the blood and liver within 24 hours. By prolonging bioavailability, MSC-EVs encapsulated in tetra-PEG hydrogels improved the antifibrotic, anti-apoptic, anti-inflammatory, and regenerative effects of EVs by almost $50 \%$, compared to FreeEVs (189).

\section{THE APPLICATIONS OF MSCS AND MSC- EVS IN THERAPEUTIC TRIALS}

Currently, MSCs are widely used in therapeutic clinical trials, especially in neurological (190), joint (191) and cardiovascular systems (192). In addition, several studies have focused on the therapeutic effects of MSCs in COVID-19 (193). In clinical trials focusing on liver diseases, both allogenic and autologous MSCs were used and bone marrow-derived MSCs were most commonly used, followed by umbilical cord-derived MSCs and adipose-derived mesenchymal stem cells (Table 2). Intravenous injection is the most commonly used method for delivering MSCs to the liver. Besides, some research chose hepatic arterial injection. Moreover, one study delivered MSCs to the liver through intrahepatic injection (196). Although these therapeutic trials used different cell types and delivery routes, they all demonstrated the safety of MSC treatments, and MSC treatment showed improvements in liver function and clinical symptoms. However, there are still some issues to be solved, such as the most effective doses via different routes (209).

Clinical trials of MSC-EV treatments are relatively few and mostly in progress. A prospective nonrandomized open-label cohort study focused on the safety and efficacy of allogeneic bone marrow MSC-EVs as a treatment for severe COVID-19 (210). In this research, the authors reported that no adverse events were observed within $72 \mathrm{~h}$ of MSC-EV intravenous injection, and MSC-EV treatment improved oxygenation, downregulated the cytokine storm, and reconstituted immunity. Another study also verified the safety of nebulized clinical-grade (211). However, there is no registered clinical research on clinical trials focusing on MSC-EVs in liver diseases.

\section{REFERENCES}

1. Asrani SK, Devarbhavi H, Eaton J, Kamath PS. Burden of Liver Diseases in the World. J Hepatol (2019) 70(1):151-71. doi: 10.1016/j.jhep.2018.09.014

2. Yang JD, Hainaut P, Gores GJ, Amadou A, Plymoth A, Roberts LR. A Global View of Hepatocellular Carcinoma: Trends, Risk, Prevention and Management. Nat Rev Gastroenterol Hepatol (2019) 16(10):589-604. doi: 10.1038/s41575-019-0186-y

3. Tsochatzis EA, Bosch J, Burroughs AK. Liver Cirrhosis. Lancet (London England) (2014) 383(9930):1749-61. doi: 10.1016/S0140-6736(14)60121-5

4. Lo Sicco C, Reverberi D, Balbi C, Ulivi V, Principi E, Pascucci L, et al. Mesenchymal Stem Cell-Derived Extracellular Vesicles as Mediators of

\section{CONCLUSIONS}

MSCs play an important role in immune modulation, and recent research has suggested that the functions of MSCs are partly but significantly dependent on paracrine effects and secretory components. MSC-EVs, as the main component of MSC paracrine substances, have shown functions in immune modulation. The liver is the core metabolic and immune organ in the human body, and the loss of immune homeostasis can lead to various liver diseases. Recently, there have been many studies on MSC-EV therapy in liver diseases. However, there is little research deeply exploring the mechanism. Some research revealed the potential immunosuppressive effects of MSC-EVs in liver diseases through the modulation of macrophages and $\mathrm{T}$ cells, while the immune reaction and immune regulation of the liver is a comprehensive process of various innate and adaptive immune responses. Thus, it is necessary to explore whether MSC-EVs influence other immune cells, such as DCs, NK cells and B cells and how they modulate the intercellular communication between immune cells in various liver diseases.

Due to the characteristics of small size, relative stability and low immunogenicity, MSC-EVs are regarded as ideal drugdelivery vesicles and have shown therapeutic effects in preclinical research. However, there is still a long journey to clinical applications, mainly because of the issues of heterogeneity and short half-life. Currently, there is no registered clinical research on clinical trials focusing on MSCEVs in liver diseases. We expect MSC-EVs to serve as an effective clinical therapy for liver diseases in the future.

\section{AUTHOR CONTRIBUTIONS}

RW and XF have organized the original manuscripts. All authors contributed to the article and approved the submitted version.

\section{FUNDING}

This work was supported by the National Natural Science Foundation of China (No. 82070582 to LY) and the 1.3.5 project for disciplines of excellence, West China Hospital, Sichuan University (No. ZYGD20012 to LY).

Anti-Inflammatory Effects: Endorsement of Macrophage Polarization Stem Cells Trans Med (2017) 6(3):1018-28. doi: 10.1002/sctm.16-0363

5. Jung YJ, Ju SY, Yoo ES, Cho SJ, Cho KA, Woo SY, et al. Msc-Dc Interactions: Msc Inhibit Maturation and Migration of Bm-Derived Dc. Cytotherapy (2007) 9(5):451-8. doi: 10.1080/14653240701452057

6. Aggarwal S, Pittenger MF. Human Mesenchymal Stem Cells Modulate Allogeneic Immune Cell Responses. Blood (2005) 105(4):1815-22. doi: 10.1182/blood-2004-04-1559

7. de Witte SFH, Luk F, Sierra Parraga JM, Gargesha M, Merino A, Korevaar SS, et al. Immunomodulation by Therapeutic Mesenchymal Stromal Cells (Msc) Is Triggered Through Phagocytosis of Msc by Monocytic Cells. Stem Cells (Dayton Ohio) (2018) 36(4):602-15. doi: 10.1002/stem.2779 
8. Duffy MM, Ritter T, Ceredig R, Griffin MD. Mesenchymal Stem Cell Effects on T-Cell Effector Pathways. Stem Cell Res Ther (2011) 2(4):34. doi: 10.1186/scrt75

9. Khare D, Or R, Resnick I, Barkatz C, Almogi-Hazan O, Avni B. Mesenchymal Stromal Cell-Derived Exosomes Affect Mrna Expression and Function of B-Lymphocytes. Front Immunol (2018) 9:3053. doi: 10.3389 /fimmu.2018.03053

10. Heymann F, Tacke F. Immunology in the Liver-from Homeostasis to Disease. Nat Rev Gastroenterol Hepatol (2016) 13(2):88-110. doi: 10.1038/ nrgastro.2015.200

11. Shi M, Zhang Z, Xu R, Lin H, Fu J, Zou Z, et al. Human Mesenchymal Stem Cell Transfusion Is Safe and Improves Liver Function in Acute-On-Chronic Liver Failure Patients. Stem Cells Trans Med (2012) 1(10):725-31. doi: 10.5966/sctm.2012-0034

12. Suk KT, Yoon J-H, Kim MY, Kim CW, Kim JK, Park H, et al. Transplantation With Autologous Bone Marrow-Derived Mesenchymal Stem Cells for Alcoholic Cirrhosis: Phase 2 Trial. Hepatol (Baltimore Md) (2016) 64(6):2185-97. doi: 10.1002/hep.28693

13. Raposo G, Stoorvogel W. Extracellular Vesicles: Exosomes, Microvesicles, and Friends. J Cell Biol (2013) 200(4):373-83. doi: 10.1083/jcb.201211138

14. Wiklander OPB, Nordin JZ, O'Loughlin A, Gustafsson Y, Corso G, Mäger I, et al. Extracellular Vesicle in Vivo Biodistribution Is Determined by Cell Source, Route of Administration and Targeting. J Extracell Vesicles (2015) 4:26316. doi: $10.3402 /$ jev.v4.26316

15. Pittenger MF, Mackay AM, Beck SC, Jaiswal RK, Douglas R, Mosca JD, et al. Multilineage Potential of Adult Human Mesenchymal Stem Cells. Science (New York NY) (1999) 284(5411):143-7. doi: 10.1126/science.284.5411.143

16. Friedenstein AJ, Chailakhjan RK, Lalykina KS. The Development of Fibroblast Colonies in Monolayer Cultures of Guinea-Pig Bone Marrow and Spleen Cells. Cell Tissue Kinet (1970) 3(4):393-403. doi: 10.1111/j.13652184.1970.tb00347.x

17. Caplan AI. Mesenchymal Stem Cells. J Orthopaedic Res Off Publ Orthopaedic Res Soc (1991) 9(5):641-50. doi: 10.1002/jor.1100090504

18. Horwitz EM, Prockop DJ, Fitzpatrick LA, Koo WW, Gordon PL, Neel M, et al. Transplantability and Therapeutic Effects of Bone Marrow-Derived Mesenchymal Cells in Children With Osteogenesis Imperfecta. Nat Med (1999) 5(3):309-13. doi: 10.1038/6529

19. Mushahary D, Spittler A, Kasper C, Weber V, Charwat V. Isolation, Cultivation, and Characterization of Human Mesenchymal Stem Cells. Cytomet Part A J Int Soc Analyt Cytol (2018) 93(1):19-31. doi: 10.1002/cyto.a.23242

20. Wagner W, Wein F, Seckinger A, Frankhauser M, Wirkner U, Krause U, et al. Comparative Characteristics of Mesenchymal Stem Cells From Human Bone Marrow, Adipose Tissue, and Umbilical Cord Blood. Exp Hematol (2005) 33(11):1402-16. doi: 10.1016/j.exphem.2005.07.003

21. Melief SM, Zwaginga JJ, Fibbe WE, Roelofs H. Adipose Tissue-Derived Multipotent Stromal Cells Have a Higher Immunomodulatory Capacity Than Their Bone Marrow-Derived Counterparts. Stem Cells Trans Med (2013) 2(6):455-63. doi: 10.5966/sctm.2012-0184

22. Dominici M, Le Blanc K, Mueller I, Slaper-Cortenbach I, Marini F, Krause D, et al. Minimal Criteria for Defining Multipotent Mesenchymal Stromal Cells. The International Society for Cellular Therapy Position Statement. Cytotherapy (2006) 8(4):315-7. doi: 10.1080/14653240600855905

23. Gazdic M, Volarevic V, Arsenijevic N, Stojkovic M. Mesenchymal Stem Cells: A Friend or Foe in Immune-Mediated Diseases. Stem Cell Rev Rep (2015) 11(2):280-7. doi: 10.1007/s12015-014-9583-3

24. Sheng $\mathrm{H}$, Wang $\mathrm{Y}$, Jin $\mathrm{Y}$, Zhang Q, Zhang $\mathrm{Y}$, Wang L, et al. A Critical Role of Ifngamma in Priming Msc-Mediated Suppression of T Cell Proliferation Through Up-Regulation of B7-H1. Cell Res (2008) 18(8):846-57. doi: 10.1038/cr.2008.80

25. Corcione A, Benvenuto F, Ferretti E, Giunti D, Cappiello V, Cazzanti F, et al. Human Mesenchymal Stem Cells Modulate B-Cell Functions. Blood (2006) 107(1):367-72. doi: 10.1182/blood-2005-07-2657

26. Li Y, Zhang D, Xu L, Dong L, Zheng J, Lin Y, et al. Cell-Cell Contact With Proinflammatory Macrophages Enhances the Immunotherapeutic Effect of Mesenchymal Stem Cells in Two Abortion Models. Cell Mol Immunol (2019) 16(12):908-20. doi: 10.1038/s41423-019-0204-6

27. Shi Y, Wang Y, Li Q, Liu K, Hou J, Shao C, et al. Immunoregulatory Mechanisms of Mesenchymal Stem and Stromal Cells in Inflammatory Diseases. Nat Rev Nephrol (2018) 14(8):493-507. doi: 10.1038/s41581-0180023-5
28. Dai W, Hale SL, Martin BJ, Kuang J-Q, Dow JS, Wold LE, et al. Allogeneic Mesenchymal Stem Cell Transplantation in Postinfarcted Rat Myocardium: Short- and Long-Term Effects. Circulation (2005) 112(2):214-23. doi: 10.1161/CIRCULATIONAHA.104.527937

29. Lee RH, Seo MJ, Pulin AA, Gregory CA, Ylostalo J, Prockop DJ. The Cd34-Like Protein Podxl and Alpha6-Integrin (Cd49f) Identify Early Progenitor Mscs With Increased Clonogenicity and Migration to Infarcted Heart in Mice. Blood (2009) 113(4):816-26. doi: 10.1182/blood-2007-12128702

30. Meirelles L, Fontes AM, Covas DT, Caplan AI. Mechanisms Involved in the Therapeutic Properties of Mesenchymal Stem Cells. Cytokine Growth Factor Rev (2009) 20(5-6):419-27. doi: 10.1016/j.cytogfr.2009.10.002

31. Zhang B, Yin Y, Lai RC, Tan SS, Choo ABH, Lim SK. Mesenchymal Stem Cells Secrete Immunologically Active Exosomes. Stem Cells Dev (2014) 23 (11):1233-44. doi: 10.1089/scd.2013.0479

32. Théry C, Witwer KW, Aikawa E, Alcaraz MJ, Anderson JD, Andriantsitohaina $\mathrm{R}$, et al. Minimal Information for Studies of Extracellular Vesicles 2018 (Misev2018): A Position Statement of the International Society for Extracellular Vesicles and Update of the Misev2014 Guidelines. J Extracell Vesicles (2018) 7(1):1535750. doi: 10.1080/20013078.2018.1535750

33. Cocucci E, Meldolesi J. Ectosomes and Exosomes: Shedding the Confusion Between Extracellular Vesicles. Trends Cell Biol (2015) 25(6):364-72. doi: 10.1016/j.tcb.2015.01.004

34. Lötvall J, Hill AF, Hochberg F, Buzás EI, Di Vizio D, Gardiner C, et al. Minimal Experimental Requirements for Definition of Extracellular Vesicles and Their Functions: A Position Statement From the International Society for Extracellular Vesicles. J Extracell Vesicles (2014) 3:26913. doi: 10.3402/ jev.v3.26913

35. de Gassart A, Geminard C, Fevrier B, Raposo G, Vidal M. Lipid RaftAssociated Protein Sorting in Exosomes. Blood (2003) 102(13):4336-44. doi 10.1182/blood-2003-03-0871

36. Batista BS, Eng WS, Pilobello KT, Hendricks-Muñoz KD, Mahal LK. Identification of a Conserved Glycan Signature for Microvesicles. J Proteome Res (2011) 10(10):4624-33. doi: 10.1021/pr200434y

37. Perez-Hernandez D, Gutiérrez-Vázquez C, Jorge I, López-Martín S, Ursa A Sánchez-Madrid F, et al. The Intracellular Interactome of TetraspaninEnriched Microdomains Reveals Their Function as Sorting Machineries Toward Exosomes. J Biol Chem (2013) 288(17):11649-61. doi: 10.1074/ jbc.M112.445304

38. Gastpar R, Gehrmann M, Bausero MA, Asea A, Gross C, Schroeder JA, et al. Heat Shock Protein 70 Surface-Positive Tumor Exosomes Stimulate Migratory and Cytolytic Activity of Natural Killer Cells. Cancer Res (2005) 65(12):5238-47. doi: 10.1158/0008-5472.CAN-04-3804

39. Xu W, Yang Z, Lu N. From Pathogenesis to Clinical Application: Insights Into Exosomes as Transfer Vectors in Cancer. J Exp Clin Cancer Res CR (2016) 35(1):156. doi: 10.1186/s13046-016-0429-5

40. Zhang B, Shen L, Shi H, Pan Z, Wu L, Yan Y, et al. Exosomes From Human Umbilical Cord Mesenchymal Stem Cells: Identification, Purification, and Biological Characteristics. Stem Cells Int (2016) 2016:1929536. doi: 10.1155/ 2016/1929536

41. Harrell CR, Jovicic N, Djonov V, Arsenijevic N, Volarevic V. Mesenchymal Stem Cell-Derived Exosomes and Other Extracellular Vesicles as New Remedies in the Therapy of Inflammatory Diseases. Cells (2019) 8 (12):1605. doi: 10.3390/cells8121605

42. Ramos T L, Sánchez-Abarca LI, Muntión S, Preciado S, Puig N, LópezRuano G, et al. Msc Surface Markers (Cd44, Cd73, and Cd90) Can Identify Human Msc-Derived Extracellular Vesicles by Conventional Flow Cytometry. Cell Commun Signaling CCS (2016) 14:2. doi: 10.1186/s12964015-0124-8

43. Mills CD, Kincaid K, Alt JM, Heilman MJ, Hill AM. M-1/M-2 Macrophages and the Th1/Th2 Paradigm. J Immunol (Baltimore Md 1950) (2000) 164 (12):6166-73. doi: 10.4049/jimmunol.164.12.6166

44. Curtale G, Rubino M, Locati M. Micrornas as Molecular Switches in Macrophage Activation. Front Immunol (2019) 10:799. doi: 10.3389/ fimmu.2019.00799

45. Murray PJ, Allen JE, Biswas SK, Fisher EA, Gilroy DW, Goerdt S, et al. Macrophage Activation and Polarization: Nomenclature and Experimental 
Guidelines. Immunity (2014) 41(1):14-20. doi: 10.1016/j.immuni.2014. 06.008

46. Wang Y, Han B, Wang Y, Wang C, Zhang H, Xue J, et al. Mesenchymal Stem Cell-Secreted Extracellular Vesicles Carrying Tgf-B1 Up-Regulate Mir-132 and Promote Mouse M2 Macrophage Polarization. J Cell Mol Med (2020) 24 (21):12750-64. doi: $10.1111 / \mathrm{jcmm} .15860$

47. Yao M, Cui B, Zhang W, Ma W, Zhao G, Xing L. Exosomal Mir-21 Secreted by Il-1 $\beta$-Primed-Mesenchymal Stem Cells Induces Macrophage M2 Polarization and Ameliorates Sepsis. Life Sci (2021) 264:118658. doi: $10.1016 /$ j.lfs.2020.118658

48. Ren W, Hou J, Yang C, Wang H, Wu S, Wu Y, et al. Extracellular Vesicles Secreted by Hypoxia Pre-Challenged Mesenchymal Stem Cells Promote Non-Small Cell Lung Cancer Cell Growth and Mobility as Well as Macrophage M2 Polarization Via Mir-21-5p Delivery. J Exp Clin Cancer Res CR (2019) 38(1):62. doi: 10.1186/s13046-019-1027-0

49. Favaro E, Carpanetto A, Caorsi C, Giovarelli M, Angelini C, Cavallo-Perin P, et al. Human Mesenchymal Stem Cells and Derived Extracellular Vesicles Induce Regulatory Dendritic Cells in Type 1 Diabetic Patients. Diabetologia (2016) 59(2):325-33. doi: 10.1007/s00125-015-3808-0

50. Reis M, Mavin E, Nicholson L, Green K, Dickinson AM, Wang X-N. Mesenchymal Stromal Cell-Derived Extracellular Vesicles Attenuate Dendritic Cell Maturation and Function. Front Immunol (2018) 9:2538. doi: $10.3389 /$ fimmu.2018.02538

51. Fan Y, Herr F, Vernochet A, Mennesson B, Oberlin E, Durrbach A. Human Fetal Liver Mesenchymal Stem Cell-Derived Exosomes Impair Natural Killer Cell Function. Stem Cells Dev (2019) 28(1):44-55. doi: 10.1089/ scd.2018.0015

52. Gomzikova MO, Kletukhina SK, Kurbangaleeva SV, Neustroeva OA, Vasileva OS, Garanina EE, et al. Mesenchymal Stem Cell Derived Biocompatible Membrane Vesicles Demonstrate Immunomodulatory Activity Inhibiting Activation and Proliferation of Human Mononuclear Cells. Pharmaceutics (2020) 12(6):577. doi: 10.3390/pharmaceutics12060577

53. Kumar BV, Connors TJ, Farber DL. Human T Cell Development, Localization, and Function Throughout Life. Immunity (2018) 48(2):20213. doi: $10.1016 /$ j.immuni.2018.01.007

54. Travis MA, Sheppard D. Tgf-B Activation and Function in Immunity. Annu Rev Immunol (2014) 32:51-82. doi: 10.1146/annurev-immunol-032713-120257

55. Crain SK, Robinson SR, Thane KE, Davis AM, Meola DM, Barton BA, et al. Extracellular Vesicles From Wharton's Jelly Mesenchymal Stem Cells Suppress Cd4 Expressing T Cells Through Transforming Growth Factor Beta and Adenosine Signaling in a Canine Model. Stem Cells Dev (2019) 28 (3):212-26. doi: 10.1089/scd.2018.0097

56. Álvarez V, Sánchez-Margallo FM, Macías-García B, Gómez-Serrano M, Jorge I, Vázquez J, et al. The Immunomodulatory Activity of Extracellular Vesicles Derived From Endometrial Mesenchymal Stem Cells on Cd4+ T Cells Is Partially Mediated by Tgfbeta. J Tissue Eng Regen Med (2018) 12 (10):2088-98. doi: 10.1002/term.2743

57. Kim H, Lee MJ, Bae E-H, Ryu JS, Kaur G, Kim HJ, et al. Comprehensive Molecular Profiles of Functionally Effective Msc-Derived Extracellular Vesicles in Immunomodulation. Mol Ther J Am Soc Gene Ther (2020) 28 (7):1628-44. doi: 10.1016/j.ymthe.2020.04.020

58. Selmani Z, Naji A, Zidi I, Favier B, Gaiffe E, Obert L, et al. Human Leukocyte Antigen-G5 Secretion by Human Mesenchymal Stem Cells Is Required to Suppress T Lymphocyte and Natural Killer Function and to Induce Cd4 +Cd25highfoxp3+ Regulatory T Cells. Stem Cells (Dayton Ohio) (2008) 26 (1):212-22. doi: 10.1634/stemcells.2007-0554

59. Park M-J, Shin J-S, Kim Y-H, Hong S-H, Yang S-H, Shin J-Y, et al. Murine Mesenchymal Stem Cells Suppress T Lymphocyte Activation Through Il-2 Receptor A (Cd25) Cleavage by Producing Matrix Metalloproteinases. Stem Cell Rev Rep (2011) 7(2):381-93. doi: 10.1007/s12015-010-9203-9

60. Cosenza S, Toupet K, Maumus M, Luz-Crawford P, Blanc-Brude O, Jorgensen C, et al. Mesenchymal Stem Cells-Derived Exosomes Are More Immunosuppressive Than Microparticles in Inflammatory Arthritis. Theranostics (2018) 8(5):1399-410. doi: 10.7150/thno.21072

61. Riazifar M, Mohammadi MR, Pone EJ, Yeri A, Lässer C, Segaliny AI, et al. Stem Cell-Derived Exosomes as Nanotherapeutics for Autoimmune and Neurodegenerative Disorders. ACS Nano (2019) 13(6):6670-88. doi: 10.1021 /acsnano.9b01004
62. Wu R, Liu C, Deng X, Chen L, Hao S, Ma L. Enhanced Alleviation of Agvhd by Tgf-B1-Modified Mesenchymal Stem Cells in Mice Through Shifting M $\varphi$ Into M2 Phenotype and Promoting the Differentiation of Treg Cells. J Cell Mol Med (2020) 24(2):1684-99. doi: 10.1111/jcmm.14862

63. Du Y-M, Zhuansun Y-X, Chen R, Lin L, Lin Y, Li J-G. Mesenchymal Stem Cell Exosomes Promote Immunosuppression of Regulatory T Cells in Asthma. Exp Cell Res (2018) 363(1):114-20. doi: 10.1016/j.yexcr.2017. 12.021

64. Song T, Eirin A, Zhu X, Zhao Y, Krier JD, Tang H, et al. Mesenchymal Stem Cell-Derived Extracellular Vesicles Induce Regulatory T Cells to Ameliorate Chronic Kidney Injury. Hyperten (Dallas Tex 1979) (2020) 75(5):1223-32. doi: 10.1161/HYPERTENSIONAHA.119.14546

65. Zhang B, Yeo RWY, Lai RC, Sim EWK, Chin KC, Lim SK. Mesenchymal Stromal Cell Exosome-Enhanced Regulatory T-Cell Production Through an Antigen-Presenting Cell-Mediated Pathway. Cytotherapy (2018) 20(5):68796. doi: 10.1016/j.jcyt.2018.02.372

66. Lai P, Chen X, Guo L, Wang Y, Liu X, Liu Y, et al. A Potent Immunomodulatory Role of Exosomes Derived From Mesenchymal Stromal Cells in Preventing Cgvhd. J Hematol Oncol (2018) 11(1):135. doi: 10.1186/s13045-018-0680-7

67. Monguió-Tortajada M, Roura S, Gálvez-Montón C, Pujal JM, Aran G, Sanjurjo L, et al. Nanosized Ucmsc-Derived Extracellular Vesicles But Not Conditioned Medium Exclusively Inhibit the Inflammatory Response of Stimulated T Cells: Implications for Nanomedicine. Theranostics (2017) 7 (2):270-84. doi: 10.7150/thno.16154

68. Wang R-X, Yu C-R, Dambuza IM, Mahdi RM, Dolinska MB, Sergeev YV, et al. Interleukin-35 Induces Regulatory B Cells That Suppress Autoimmune Disease. Nat Med (2014) 20(6):633-41. doi: 10.1038/nm.3554

69. Franquesa M, Mensah FK, Huizinga R, Strini T, Boon L, Lombardo E, et al. Human Adipose Tissue-Derived Mesenchymal Stem Cells Abrogate Plasmablast Formation and Induce Regulatory B Cells Independently of T Helper Cells. Stem Cells (Dayton Ohio) (2015) 33(3):880-91. doi: 10.1002/ stem. 1881

70. Guo L, Lai P, Wang Y, Huang T, Chen X, Geng S, et al. Extracellular Vesicles Derived From Mesenchymal Stem Cells Prevent Skin Fibrosis in the Cgvhd Mouse Model by Suppressing the Activation of Macrophages and B Cells Immune Response. Int Immunopharmacol (2020) 84:106541. doi: 10.1016/ j.intimp.2020.106541

71. Adamo A, Brandi J, Caligola S, Delfino P, Bazzoni R, Carusone R, et al. Extracellular Vesicles Mediate Mesenchymal Stromal Cell-Dependent Regulation of B Cell Pi3k-Akt Signaling Pathway and Actin Cytoskeleton. Front Immunol (2019) 10:446. doi: 10.3389/fimmu.2019.00446

72. Racanelli V, Rehermann B. The Liver as an Immunological Organ. Hepatol (Baltimore Md) (2006) 43(2 Suppl 1):S54-62. doi: 10.1002/hep.21060

73. Moshage H. Cytokines and the Hepatic Acute Phase Response. J Pathol (1997) 181(3):257-66. doi: 10.1002/(sici) 1096-9896(199703)181:3<257::Aidpath756 >3.0.Co;2-u

74. Bilzer M, Roggel F, Gerbes AL. Role of Kupffer Cells in Host Defense and Liver Disease. Liver Int Off J Int Assoc Study Liver (2006) 26(10):1175-86. doi: $10.1111 / j .1478-3231.2006 .01342 . x$

75. Hsu W, Shu S-A, Gershwin E, Lian Z-X. The Current Immune Function of Hepatic Dendritic Cells. Cell Mol Immunol (2007) 4(5):321-8.

76. Hudspeth K, Donadon M, Cimino M, Pontarini E, Tentorio P, Preti M, et al. Human Liver-Resident Cd56(Bright)/Cd16(Neg) Nk Cells Are Retained Within Hepatic Sinusoids Via the Engagement of Ccr5 and Cxcr6 Pathways. J Autoimmun (2016) 66:40-50. doi: 10.1016/j.jaut.2015. 08.011

77. Lanier LL. Nk Cell Recognition. Annu Rev Immunol (2005) 23:225-74. doi: 10.1146/annurev.immunol.23.021704.115526

78. Bandyopadhyay K, Marrero I, Kumar V. Nkt Cell Subsets as Key Participants in Liver Physiology and Pathology. Cell Mol Immunol (2016) 13(3):337-46. doi: 10.1038/cmi.2015.115

79. Swain MG. Hepatic Nkt Cells: Friend or Foe? Clin Sci (London Engl 1979) (2008) 114(7):457-66. doi: 10.1042/cs20070328

80. Huang S, Wu J, Gao X, Zou S, Chen L, Yang X, et al. Lsecs Express Functional Nod1 Receptors: A Role for Nod1 in Lsec Maturation-Induced T Cell Immunity in Vitro. Mol Immunol (2018) 101:167-75. doi: 10.1016/ j.molimm.2018.06.002 
81. Cormier EG, Tsamis F, Kajumo F, Durso RJ, Gardner JP, Dragic T. Cd81 Is an Entry Coreceptor for Hepatitis C Virus. Proc Natl Acad Sci USA (2004) 101(19):7270-4. doi: 10.1073/pnas.0402253101

82. Harrington LE, Hatton RD, Mangan PR, Turner H, Murphy TL, Murphy KM, et al. Interleukin 17-Producing Cd4+ Effector T Cells Develop Via a Lineage Distinct From the T Helper Type 1 and 2 Lineages. Nat Immunol (2005) 6(11):1123-32. doi: 10.1038/ni1254

83. Wang L, Sun Y, Zhang Z, Jia Y, Zou Z, Ding J, et al. Cxcr5+ Cd4+ T Follicular Helper Cells Participate in the Pathogenesis of Primary Biliary Cirrhosis. Hepatol (Baltimore Md) (2015) 61(2):627-38. doi: 10.1002/hep.27306

84. Carambia A, Freund B, Schwinge D, Bruns OT, Salmen SC, Ittrich H, et al. Nanoparticle-Based Autoantigen Delivery to Treg-Inducing Liver Sinusoidal Endothelial Cells Enables Control of Autoimmunity in Mice. J Hepatol (2015) 62(6):1349-56. doi: 10.1016/j.jhep.2015.01.006

85. Wong YC, Tay SS, McCaughan GW, Bowen DG, Bertolino P. Immune Outcomes in the Liver: Is Cd8 T Cell Fate Determined by the Environment? J Hepatol (2015) 63(4):1005-14. doi: 10.1016/j.jhep.2015.05.033

86. Hunter S, Willcox CR, Davey MS, Kasatskaya SA, Jeffery HC, Chudakov DM, et al. Human Liver Infiltrating $\Gamma \delta \mathrm{T}$ Cells Are Composed of Clonally Expanded Circulating and Tissue-Resident Populations. J Hepatol (2018) 69 (3):654-65. doi: 10.1016/j.jhep.2018.05.007

87. Ezzelarab M, Thomson AW. Tolerogenic Dendritic Cells and Their Role in Transplantation. Semin Immunol (2011) 23(4):252-63. doi: 10.1016/ j.smim.2011.06.007

88. You Q, Cheng L, Kedl RM, Ju C. Mechanism of T Cell Tolerance Induction by Murine Hepatic Kupffer Cells. Hepatol (Baltimore Md) (2008) 48(3):97890. doi: 10.1002/hep.22395

89. Huang L-R, Wohlleber D, Reisinger F, Jenne CN, Cheng R-L, Abdullah Z, et al. Intrahepatic Myeloid-Cell Aggregates Enable Local Proliferation of Cd8 (+) T Cells and Successful Immunotherapy Against Chronic Viral Liver Infection. Nat Immunol (2013) 14(6):574-83. doi: 10.1038/ni.2573

90. Hernandez C, Huebener P, Pradere J-P, Antoine DJ, Friedman RA, Schwabe RF. Hmgb1 Links Chronic Liver Injury to Progenitor Responses and Hepatocarcinogenesis. J Clin Invest (2018) 128(6):2436-51. doi: 10.1172/ JCI91786

91. Yazdani HO, Chen H-W, Tohme S, Tai S, van der Windt DJ, Loughran P, et al. Il-33 Exacerbates Liver Sterile Inflammation by Amplifying Neutrophil Extracellular Trap Formation. J Hepatol (2017) 68(1):P130-9. doi: 10.1016/ j.jhep.2017.09.010

92. Mridha AR, Wree A, Robertson AAB, Yeh MM, Johnson CD, Van Rooyen DM, et al. Nlrp3 Inflammasome Blockade Reduces Liver Inflammation and Fibrosis in Experimental Nash in Mice. J Hepatol (2017) 66(5):1037-46. doi: 10.1016/j.jhep.2017.01.022

93. Kesar V, Odin JA. Toll-Like Receptors and Liver Disease. Liver Int Off J Int Assoc Study Liver (2014) 34(2):184-96. doi: 10.1111/liv.12315

94. Thorgersen EB, Barratt-Due A, Haugaa H, Harboe M, Pischke SE, Nilsson $\mathrm{PH}$, et al. The Role of Complement in Liver Injury, Regeneration, and Transplantation. Hepatol (Baltimore Md) (2019) 70(2):725-36. doi: 10.1002/ hep. 30508

95. Zhao H, Shang Q, Pan Z, Bai Y, Li Z, Zhang H, et al. Exosomes From Adipose-Derived Stem Cells Attenuate Adipose Inflammation and Obesity Through Polarizing M2 Macrophages and Beiging in White Adipose Tissue. Diabetes (2018) 67(2):235-47. doi: 10.2337/db17-0356

96. Lu F-B, Chen D-Z, Chen L, Hu E-D, Wu J-L, Li H, et al. Attenuation of Experimental Autoimmune Hepatitis in Mice With Bone Mesenchymal Stem Cell-Derived Exosomes Carrying Microrna-223-3p. Mol Cells (2019) 42(12):906-18. doi: 10.14348/molcells.2019.2283

97. Liu Y, Lou G, Li A, Zhang T, Qi J, Ye D, et al. Amsc-Derived Exosomes Alleviate Lipopolysaccharide/D-Galactosamine-Induced Acute Liver Failure by Mir-17-Mediated Reduction of Txnip/Nlrp3 Inflammasome Activation in Macrophages. EBioMedicine (2018) 36:140-50. doi: 10.1016/ j.ebiom.2018.08.054

98. Zhang S, Jiang L, Hu H, Wang H, Wang X, Jiang J, et al. Pretreatment of Exosomes Derived From Hucmscs With Tnf-A Ameliorates Acute Liver Failure by Inhibiting the Activation of Nlrp3 in Macrophage. Life Sci (2020) 246:117401. doi: 10.1016/j.lfs.2020.117401

99. Shao M, Xu Q, Wu Z, Chen Y, Shu Y, Cao X, et al. Exosomes Derived From Human Umbilical Cord Mesenchymal Stem Cells Ameliorate Il-6-Induced
Acute Liver Injury Through Mir-455-3p. Stem Cell Res Ther (2020) 11(1):37. doi: 10.1186/s13287-020-1550-0

100. Zheng J, Lu T, Zhou C, Cai J, Zhang X, Liang J, et al. Extracellular Vesicles Derived From Human Umbilical Cord Mesenchymal Stem Cells Protect Liver Ischemia/Reperfusion Injury by Reducing Cd154 Expression on Cd4+ T Cells Via Cct2. Adv Sci (Weinh) (2020) 7(18):1903746. doi: 10.1002/ advs.201903746

101. Xie K, Liu L, Chen J, Liu F. Exosomal Mir-1246 Derived From Human Umbilical Cord Blood Mesenchymal Stem Cells Attenuates Hepatic Ischemia Reperfusion Injury by Modulating T Helper 17/Regulatory T Balance. IUBMB Life (2019) 71(12):2020-30. doi: 10.1002/iub.2147

102. Younossi ZM, Koenig AB, Abdelatif D, Fazel Y, Henry L, Wymer M. Global Epidemiology of Nonalcoholic Fatty Liver Disease-Meta-Analytic Assessment of Prevalence, Incidence, and Outcomes. Hepatol (Baltimore Md) (2016) 64(1):73-84. doi: 10.1002/hep.28431

103. Younossi Z, Anstee QM, Marietti M, Hardy T, Henry L, Eslam M, et al. Global Burden of Nafld and Nash: Trends, Predictions, Risk Factors and Prevention. Nat Rev Gastroenterol Hepatol (2018) 15(1):11-20. doi: 10.1038/ nrgastro.2017.109

104. Schuster S, Cabrera D, Arrese M, Feldstein AE. Triggering and Resolution of Inflammation in Nash. Nat Rev Gastroenterol Hepatol (2018) 15(6):349-64. doi: 10.1038/s41575-018-0009-6

105. Baeck C, Wehr A, Karlmark KR, Heymann F, Vucur M, Gassler N, et al. Pharmacological Inhibition of the Chemokine Ccl2 (Mcp-1) Diminishes Liver Macrophage Infiltration and Steatohepatitis in Chronic Hepatic Injury. Gut (2012) 61(3):416-26. doi: 10.1136/gutjnl-2011-300304

106. Leroux A, Ferrere G, Godie V, Cailleux F, Renoud M-L, Gaudin F, et al. Toxic Lipids Stored by Kupffer Cells Correlates With Their Pro-Inflammatory Phenotype at an Early Stage of Steatohepatitis. J Hepatol (2012) 57(1):141-9. doi: 10.1016/j.jhep.2012.02.028

107. Rensen SS, Slaats Y, Nijhuis J, Jans A, Bieghs V, Driessen A, et al. Increased Hepatic Myeloperoxidase Activity in Obese Subjects With Nonalcoholic Steatohepatitis. Am J Pathol (2009) 175(4):1473-82. doi: 10.2353/ ajpath.2009.080999

108. Henning JR, Graffeo CS, Rehman A, Fallon NC, Zambirinis CP, Ochi A, et al. Dendritic Cells Limit Fibroinflammatory Injury in Nonalcoholic Steatohepatitis in Mice. Hepatol (Baltimore Md) (2013) 58(2):589-602. doi: $10.1002 /$ hep. 26267

109. Friedman SL, Neuschwander-Tetri BA, Rinella M, Sanyal AJ. Mechanisms of Nafld Development and Therapeutic Strategies. Nat Med (2018) 24(7):90822. doi: 10.1038/s41591-018-0104-9

110. Ohara M, Ohnishi S, Hosono H, Yamamoto K, Yuyama K, Nakamura H, et al. Extracellular Vesicles From Amnion-Derived Mesenchymal Stem Cells Ameliorate Hepatic Inflammation and Fibrosis in Rats. Stem Cells Int (2018) 2018:3212643. doi: $10.1155 / 2018 / 3212643$

111. Watanabe T, Tsuchiya A, Takeuchi S, Nojiri S, Yoshida T, Ogawa M, et al. Development of a Non-Alcoholic Steatohepatitis Model With Rapid Accumulation of Fibrosis, and Its Treatment Using Mesenchymal Stem Cells and Their Small Extracellular Vesicles. Regen Ther (2020) 14:252-61. doi: 10.1016/j.reth.2020.03.012

112. Betrapally NS, Gillevet PM, Bajaj JS. Gut Microbiome and Liver Disease. Trans Res J Lab Clin Med (2017) 179:49-59. doi: 10.1016/j.trsl.2016.07.005

113. Kataru RP, Jung K, Jang C, Yang H, Schwendener RA, Baik JE, et al. Critical Role of Cd11b+ Macrophages and Vegf in Inflammatory Lymphangiogenesis, Antigen Clearance, and Inflammation Resolution. Blood (2009) 113(22):5650-9. doi: 10.1182/blood-2008-09-176776

114. El-Derany MO, AbdelHamid SG. Upregulation of Mir-96-5p by Bone Marrow Mesenchymal Stem Cells and Their Exosomes Alleviate NonAlcoholic Steatohepatitis: Emphasis on Caspase-2 Signaling Inhibition. Biochem Pharmacol (2021) 190:114624. doi: 10.1016/j.bcp.2021.114624

115. He Q, Wang L, Zhao R, Yan F, Sha S, Cui C, et al. Mesenchymal Stem CellDerived Exosomes Exert Ameliorative Effects in Type 2 Diabetes by Improving Hepatic Glucose and Lipid Metabolism Via Enhancing Autophagy. Stem Cell Res Ther (2020) 11(1):223. doi: 10.1186/s13287-020-01731-6

116. Schmeltzer PA, Russo MW. Clinical Narrative: Autoimmune Hepatitis. Am J Gastroenterol (2018) 113(7):951-8. doi: 10.1038/s41395-018-0058-z

117. Mack CL, Adams D, Assis DN, Kerkar N, Manns MP, Mayo MJ, et al. Diagnosis and Management of Autoimmune Hepatitis in Adults and 
Children: 2019 Practice Guidance and Guidelines From the American Association for the Study of Liver Diseases. Hepatol (Baltimore Md) (2020) 72(2):671-722. doi: 10.1002/hep.31065

118. Mieli-Vergani G, Vergani D, Czaja AJ, Manns MP, Krawitt EL, Vierling JM, et al. Autoimmune Hepatitis. Nat Rev Dis Primers (2018) 4:18017. doi: 10.1038/nrdp.2018.17

119. Christen U, Hintermann E. Autoantibodies in Autoimmune Hepatitis: Can Epitopes Tell Us About the Etiology of the Disease? Front Immunol (2018) 9:163. doi: $10.3389 /$ fimmu.2018.00163

120. Liberal R, Grant CR, Holder BS, Cardone J, Martinez-Llordella M, Ma Y, et al. In Autoimmune Hepatitis Type 1 or the Autoimmune HepatitisSclerosing Cholangitis Variant Defective Regulatory T-Cell Responsiveness to Il-2 Results in Low Il-10 Production and Impaired Suppression. Hepatol (Baltimore Md) (2015) 62(3):863-75. doi: 10.1002/hep.27884

121. Tamura R, Uemoto S, Tabata Y. Immunosuppressive Effect of Mesenchymal Stem Cell-Derived Exosomes on a Concanavalin a-Induced Liver Injury Model. Inflammation Regen (2016) 36:26. doi: 10.1186/s41232-016-0030-5

122. Chen L, Lu F-B, Chen D-Z, Wu J-L, Hu E-d, Xu L-M, et al. Bmscs-Derived Mir-223-Containing Exosomes Contribute to Liver Protection in Experimental Autoimmune Hepatitis. Mol Immunol (2018) 93:38-46. doi: 10.1016/j.molimm.2017.11.008

123. Stravitz RT, Lee WM. Acute Liver Failure. Lancet (London England) (2019) 394(10201):869-81. doi: 10.1016/S0140-6736(19)31894-X

124. Antoniades CG, Quaglia A, Taams LS, Mitry RR, Hussain M, Abeles R, et al. Source and Characterization of Hepatic Macrophages in AcetaminophenInduced Acute Liver Failure in Humans. Hepatol (Baltimore Md) (2012) 56 (2):735-46. doi: 10.1002/hep. 25657

125. You Q, Holt M, Yin H, Li G, Hu C-J, Ju C. Role of Hepatic Resident and Infiltrating Macrophages in Liver Repair After Acute Injury. Biochem Pharmacol (2013) 86(6):836-43. doi: 10.1016/j.bcp.2013.07.006

126. Jiang L, Zhang S, Hu H, Yang J, Wang X, Ma Y, et al. Exosomes Derived From Human Umbilical Cord Mesenchymal Stem Cells Alleviate Acute Liver Failure by Reducing the Activity of the Nlrp3 Inflammasome in Macrophages. Biochem Biophys Res Commun (2019) 508(3):735-41. doi: $10.1016 / j . b b r c .2018 .11 .189$

127. Chen L, Xiang B, Wang X, Xiang C. Exosomes Derived From Human Menstrual Blood-Derived Stem Cells Alleviate Fulminant Hepatic Failure. Stem Cell Res Ther (2017) 8(1):9. doi: 10.1186/s13287-016-0453-6

128. Zhao S, Liu Y, Pu Z. Bone Marrow Mesenchymal Stem Cell-Derived Exosomes Attenuate D-Gain/Lps-Induced Hepatocyte Apoptosis by Activating Autophagy in Vitro. Drug Design Dev Ther (2019) 13:2887-97. doi: 10.2147/DDDT.S220190

129. Yan Y, Jiang W, Tan Y, Zou S, Zhang H, Mao F, et al. Hucmsc ExosomeDerived Gpx1 Is Required for the Recovery of Hepatic Oxidant Injury. Mol Ther J Am Soc Gene Ther (2017) 25(2):465-79. doi: 10.1016/j.ymthe.2016.11.019

130. Jiang W, Tan Y, Cai M, Zhao T, Mao F, Zhang X, et al. Human Umbilical Cord Msc-Derived Exosomes Suppress the Development of Ccl-Induced Liver Injury Through Antioxidant Effect. Stem Cells Int (2018) 2018:6079642. doi: 10.1155/2018/6079642

131. Tan CY, Lai RC, Wong W, Dan YY, Lim S-K, Ho HK. Mesenchymal Stem Cell-Derived Exosomes Promote Hepatic Regeneration in Drug-Induced Liver Injury Models. Stem Cell Res Ther (2014) 5(3):76. doi: 10.1186/scrt465

132. Wu H-H, Lee OK. Exosomes From Mesenchymal Stem Cells Induce the Conversion of Hepatocytes Into Progenitor Oval Cells. Stem Cell Res Ther (2017) 8(1):117. doi: 10.1186/s13287-017-0560-Z

133. Damania A, Jaiman D, Teotia AK, Kumar A. Mesenchymal Stromal CellDerived Exosome-Rich Fractionated Secretome Confers a Hepatoprotective Effect in Liver Injury. Stem Cell Res Ther (2018) 9(1):31. doi: 10.1186/s13287017-0752-6

134. Friedman SL. Liver Fibrosis - From Bench to Bedside. J Hepatol (2003) 38 Suppl 1:S38-53. doi: 10.1016/S0168-8278(02)00429-4

135. Iwaisako K, Jiang C, Zhang M, Cong M, Moore-Morris TJ, Park TJ, et al. Origin of Myofibroblasts in the Fibrotic Liver in Mice. Proc Natl Acad Sci USA (2014) 111(32):E3297-305. doi: 10.1073/pnas.1400062111

136. Ge W-S, Wang Y-J, Wu J-X, Fan J-G, Chen Y-W, Zhu L. B-Catenin Is Overexpressed in Hepatic Fibrosis and Blockage of Wnt/B-Catenin Signaling Inhibits Hepatic Stellate Cell Activation. Mol Med Rep (2014) 9(6):2145-51. doi: $10.3892 / \mathrm{mmr} .2014 .2099$
137. Ramachandran P, Pellicoro A, Vernon MA, Boulter L, Aucott RL, Ali A, et al. Differential Ly-6c Expression Identifies the Recruited Macrophage Phenotype, Which Orchestrates the Regression of Murine Liver Fibrosis. Proc Natl Acad Sci USA (2012) 109(46):E3186-95. doi: 10.1073/pnas. 1119964109

138. Ma P-F, Gao C-C, Yi J, Zhao J-L, Liang S-Q, Zhao Y, et al. Cytotherapy With M1-Polarized Macrophages Ameliorates Liver Fibrosis by Modulating Immune Microenvironment in Mice. J Hepatol (2017) 67(4):770-9. doi: 10.1016/j.jhep.2017.05.022

139. Zhou J, Lin Y, Kang X, Liu Z, Zhang W, Xu F. Microrna-186 in Extracellular Vesicles From Bone Marrow Mesenchymal Stem Cells Alleviates Idiopathic Pulmonary Fibrosis Via Interaction With Sox 4 and Dkk1. Stem Cell Res Ther (2021) 12(1):96. doi: 10.1186/s13287-020-02083-x

140. Bruno S, Pasquino C, Herrera Sanchez MB, Tapparo M, Figliolini F, Grange C, et al. Hlsc-Derived Extracellular Vesicles Attenuate Liver Fibrosis and Inflammation in a Murine Model of Non-Alcoholic Steatohepatitis. Mol Ther J Am Soc Gene Ther (2020) 28(2):479-89. doi: 10.1016/j.ymthe.2019.10.016

141. Wang B, Yao K, Huuskes BM, Shen H-H, Zhuang J, Godson C, et al. Mesenchymal Stem Cells Deliver Exogenous Microrna-Let7c Via Exosomes to Attenuate Renal Fibrosis. Mol Ther J Am Soc Gene Ther (2016) 24 (7):1290-301. doi: 10.1038/mt.2016.90

142. Wang S, Li L, Liu T, Jiang W, Hu X. Mir-19a/19b-Loaded Exosomes in Combination With Mesenchymal Stem Cell Transplantation in a Preclinical Model of Myocardial Infarction. Regen Med (2020) 15(6):1749-59. doi: 10.2217/rme-2019-0136

143. Mardpour S, Hassani S-N, Mardpour S, Sayahpour F, Vosough M, Ai J, et al. Extracellular Vesicles Derived From Human Embryonic Stem Cell-Mscs Ameliorate Cirrhosis in Thioacetamide-Induced Chronic Liver Injury. J Cell Physiol (2018) 233(12):9330-44. doi: 10.1002/jcp.26413

144. Li T, Yan Y, Wang B, Qian H, Zhang X, Shen L, et al. Exosomes Derived From Human Umbilical Cord Mesenchymal Stem Cells Alleviate Liver Fibrosis. Stem Cells Dev (2013) 22(6):845-54. doi: 10.1089/scd.2012.0395

145. Rong X, Liu J, Yao X, Jiang T, Wang Y, Xie F. Human Bone Marrow Mesenchymal Stem Cells-Derived Exosomes Alleviate Liver Fibrosis Through the Wnt/B-Catenin Pathway. Stem Cell Res Ther (2019) 10(1):98. doi: 10.1186/s13287-019-1204-2

146. Kim J, Lee C, Shin Y, Wang S, Han J, Kim M, et al. Sevs From Tonsil-Derived Mesenchymal Stromal Cells Alleviate Activation of Hepatic Stellate Cells and Liver Fibrosis Through Mir-486-5p. Mol Ther J Am Soc Gene Ther (2021) 29 (4):1471-86. doi: 10.1016/j.ymthe.2020.12.025

147. Du Z, Wu T, Liu L, Luo B, Wei C. Extracellular Vesicles-Derived Mir-150-5p Secreted by Adipose-Derived Mesenchymal Stem Cells Inhibits Cxcl1 Expression to Attenuate Hepatic Fibrosis. J Cell Mol Med (2021) 25 (2):701-15. doi: 10.1111/jcmm.16119

148. Peralta C, Jiménez-Castro MB, Gracia-Sancho J. Hepatic Ischemia and Reperfusion Injury: Effects on the Liver Sinusoidal Milieu. J Hepatol (2013) 59(5):1094-106. doi: 10.1016/j.jhep.2013.06.017

149. Jiménez-Castro MB, Cornide-Petronio ME, Gracia-Sancho J, Peralta C. Inflammasome-Mediated Inflammation in Liver Ischemia-Reperfusion Injury. Cells (2019) 8(10):1131. doi: 10.3390/cells8101131

150. Zhai Y, Busuttil RW, Kupiec-Weglinski JW. Liver Ischemia and Reperfusion Injury: New Insights Into Mechanisms of Innate-Adaptive ImmuneMediated Tissue Inflammation. Am J Transplant Off J Am Soc Transplant Am Soc Transplant Surgeons (2011) 11(8):1563-9. doi: 10.1111/j.16006143.2011.03579.x

151. Shen X, Wang Y, Gao F, Ren F, Busuttil RW, Kupiec-Weglinski JW, et al. Cd4 T Cells Promote Tissue Inflammation Via Cd40 Signaling Without De Novo Activation in a Murine Model of Liver Ischemia/Reperfusion Injury. Hepatology (2009) 50(5):1537-46. doi: 10.1002/hep.23153

152. Xie K, Liu L, Chen J, Liu F. Exosomes Derived From Human Umbilical Cord Blood Mesenchymal Stem Cells Improve Hepatic Ischemia Reperfusion Injury Via Delivering Mir-1246. Cell Cycle (Georgetown Tex) (2019) 18 (24):3491-501. doi: 10.1080/15384101.2019.1689480

153. Nong K, Wang W, Niu X, Hu B, Ma C, Bai Y, et al. Hepatoprotective Effect of Exosomes From Human-Induced Pluripotent Stem Cell-Derived Mesenchymal Stromal Cells Against Hepatic Ischemia-Reperfusion Injury in Rats. Cytotherapy (2016) 18(12):1548-59. doi: 10.1016/j.jcyt.2016.08.002 
154. Yang B, Duan W, Wei L, Zhao Y, Han Z, Wang J, et al. Bone Marrow Mesenchymal Stem Cell-Derived Hepatocyte-Like Cell Exosomes Reduce Hepatic Ischemia/Reperfusion Injury by Enhancing Autophagy. Stem Cells Dev (2020) 29(6):372-9. doi: 10.1089/scd.2019.0194

155. Barbash IM, Chouraqui P, Baron J, Feinberg MS, Etzion S, Tessone A, et al. Systemic Delivery of Bone Marrow-Derived Mesenchymal Stem Cells to the Infarcted Myocardium: Feasibility, Cell Migration, and Body Distribution. Circulation (2003) 108(7):863-8. doi: 10.1161/01.CIR.0000084828.50310.6A

156. Braid LR, Wood CA, Wiese DM, Ford BN. Intramuscular Administration Potentiates Extended Dwell Time of Mesenchymal Stromal Cells Compared to Other Routes. Cytotherapy (2018) 20(2):232-44. doi: 10.1016/j.jcyt.2017.09.013

157. Jung JW, Kwon M, Choi JC, Shin JW, Park IW, Choi BW, et al. Familial Occurrence of Pulmonary Embolism After Intravenous, Adipose TissueDerived Stem Cell Therapy. Yonsei Med J (2013) 54(5):1293-6. doi: 10.3349/ ymj.2013.54.5.1293

158. Rufino-Ramos D, Albuquerque PR, Carmona V, Perfeito R, Nobre RJ, Pereira de Almeida L. Extracellular Vesicles: Novel Promising Delivery Systems for Therapy of Brain Diseases. J Controlled Release Off J Controlled Release Soc (2017) 262:247-58. doi: 10.1016/j.jconrel.2017.07.001

159. Yong KW, Wan Safwani WKZ, Xu F, Wan Abas WAB, Choi JR, PingguanMurphy B. Cryopreservation of Human Mesenchymal Stem Cells for Clinical Applications: Current Methods and Challenges. Biopreserv Biobanking (2015) 13(4):231-9. doi: 10.1089/bio.2014.0104

160. Cheng Y, Zeng Q, Han Q, Xia W. Effect of Ph, Temperature and FreezingThawing on Quantity Changes and Cellular Uptake of Exosomes. Protein Cell (2019) 10(4):295-9. doi: 10.1007/s13238-018-0529-4

161. Lőrincz ÁM, Timár CI, Marosvári KA, Veres DS, Otrokocsi L, Kittel Á, et al. Effect of Storage on Physical and Functional Properties of Extracellular Vesicles Derived From Neutrophilic Granulocytes. J Extracell Vesicles (2014) 3:25465. doi: 10.3402/jev.v3.25465

162. Sotiropoulou PA, Perez SA, Salagianni M, Baxevanis CN, Papamichail M. Characterization of the Optimal Culture Conditions for Clinical Scale Production of Human Mesenchymal Stem Cells. Stem Cells (Dayton Ohio) (2006) 24(2):462-71. doi: 10.1634/stemcells.2004-0331

163. Barkholt L, Flory E, Jekerle V, Lucas-Samuel S, Ahnert P, Bisset L, et al. Risk of Tumorigenicity in Mesenchymal Stromal Cell-Based Therapies-Bridging Scientific Observations and Regulatory Viewpoints. Cytotherapy (2013) 15 (7):753-9. doi: 10.1016/j.jcyt.2013.03.005

164. Yoo J-W, Irvine DJ, Discher DE, Mitragotri S. Bio-Inspired, Bioengineered and Biomimetic Drug Delivery Carriers. Nat Rev Drug Discov (2011) 10 (7):521-35. doi: 10.1038/nrd3499

165. Lai RC, Yeo RWY, Tan KH, Lim SK. Exosomes for Drug Delivery - a Novel Application for the Mesenchymal Stem Cell. Biotechnol Adv (2013) 31 (5):543-51. doi: 10.1016/j.biotechadv.2012.08.008

166. Alvarez-Erviti L, Seow Y, Yin H, Betts C, Lakhal S, Wood MJA. Delivery of Sirna to the Mouse Brain by Systemic Injection of Targeted Exosomes. Nat Biotechnol (2011) 29(4):341-5. doi: 10.1038/nbt.1807

167. Yeo RWY, Lai RC, Zhang B, Tan SS, Yin Y, Teh BJ, et al. Mesenchymal Stem Cell: An Efficient Mass Producer of Exosomes for Drug Delivery. Adv Drug Deliv Rev (2013) 65(3):336-41. doi: 10.1016/j.addr.2012.07.001

168. Qu Y, Zhang Q, Cai X, Li F, Ma Z, Xu M, et al. Exosomes Derived From Mir181-5p-Modified Adipose-Derived Mesenchymal Stem Cells Prevent Liver Fibrosis Via Autophagy Activation. J Cell Mol Med (2017) 21(10):2491-502. doi: $10.1111 /$ jcmm. 13170

169. Lou G, Yang Y, Liu F, Ye B, Chen Z, Zheng M, et al. Mir-122 Modification Enhances the Therapeutic Efficacy of Adipose Tissue-Derived Mesenchymal Stem Cells Against Liver Fibrosis. J Cell Mol Med (2017) 21(11):2963-73. doi: $10.1111 /$ jcmm.13208

170. Tang M, Chen Y, Li B, Sugimoto H, Yang S, Yang C, et al. Therapeutic Targeting of Stat3 With Small Interference Rnas and Antisense Oligonucleotides Embedded Exosomes in Liver Fibrosis. FASEB J Off Publ Fed Am Soc Exp Biol (2021) 35(5):e21557. doi: 10.1096/fj.202002777RR

171. Zhao J, Li Y, Jia R, Wang J, Shi M, Wang Y. Mesenchymal Stem CellsDerived Exosomes as Dexamethasone Delivery Vehicles for Autoimmune Hepatitis Therapy. Front Bioeng Biotechnol (2021) 9:650376. doi: 10.3389/ fbioe.2021.650376

172. Wang Z-G, He Z-Y, Liang S, Yang Q, Cheng P, Chen A-M. Comprehensive Proteomic Analysis of Exosomes Derived From Human Bone Marrow,
Adipose Tissue, and Umbilical Cord Mesenchymal Stem Cells. Stem Cell Res Ther (2020) 11(1):511. doi: 10.1186/s13287-020-02032-8

173. Oksvold MP, Kullmann A, Forfang L, Kierulf B, Li M, Brech A, et al. Expression of B-Cell Surface Antigens in Subpopulations of Exosomes Released From B-Cell Lymphoma Cells. Clin Ther (2014) 36(6):847-62. doi: 10.1016/j.clinthera.2014.05.010

174. Roucourt B, Meeussen S, Bao J, Zimmermann P, David G. Heparanase Activates the Syndecan-Syntenin-Alix Exosome Pathway. Cell Res (2015) 25 (4):412-28. doi: 10.1038/cr.2015.29

175. van der Vlist EJ, Nolte-'t Hoen ENM, Stoorvogel W, Arkesteijn GJA, Wauben MHM. Fluorescent Labeling of Nano-Sized Vesicles Released by Cells and Subsequent Quantitative and Qualitative Analysis by HighResolution Flow Cytometry. Nat Protoc (2012) 7(7):1311-26. doi: 10.1038/ nprot.2012.065

176. Pospichalova V, Svoboda J, Dave Z, Kotrbova A, Kaiser K, Klemova D, et al. Simplified Protocol for Flow Cytometry Analysis of Fluorescently Labeled Exosomes and Microvesicles Using Dedicated Flow Cytometer. J Extracell Vesicles (2015) 4:25530. doi: 10.3402/jev.v4.25530

177. Smith ZJ, Lee C, Rojalin T, Carney RP, Hazari S, Knudson A, et al. Single Exosome Study Reveals Subpopulations Distributed Among Cell Lines With Variability Related to Membrane Content. J Extracell Vesicles (2015) 4:28533. doi: 10.3402/jev.v4.28533

178. Takahashi Y, Nishikawa M, Shinotsuka H, Matsui Y, Ohara S, Imai T, et al. Visualization and in Vivo Tracking of the Exosomes of Murine Melanoma B16-Bl6 Cells in Mice After Intravenous Injection. J Biotechnol (2013) 165 (2):77-84. doi: 10.1016/j.jbiotec.2013.03.013

179. Matsumoto A, Takahashi Y, Chang H-Y, Wu Y-W, Yamamoto A, Ishihama $\mathrm{Y}$, et al. Blood Concentrations of Small Extracellular Vesicles Are Determined by a Balance Between Abundant Secretion and Rapid Clearance. J Extracell Vesicles (2020) 9(1):1696517. doi: 10.1080/ 20013078.2019.1696517

180. Yang Z, Shi J, Xie J, Wang Y, Sun J, Liu T, et al. Large-Scale Generation of Functional Mrna-Encapsulating Exosomes Via Cellular Nanoporation. Nat Biomed Eng (2020) 4(1):69-83. doi: 10.1038/s41551-019-0485-1

181. Imai T, Takahashi Y, Nishikawa M, Kato K, Morishita M, Yamashita T, et al. Macrophage-Dependent Clearance of Systemically Administered B16bl6Derived Exosomes From the Blood Circulation in Mice. J Extracell Vesicles (2015) 4:26238. doi: 10.3402/jev.v4.26238

182. Hoffman AS. Hydrogels for Biomedical Applications. Adv Drug Deliv Rev (2002) 54(1):3-12. doi: 10.1016/S0169-409X(01)00239-3

183. Li J, Mooney DJ. Designing Hydrogels for Controlled Drug Delivery. Nat Rev Mater (2016) 1(12):16071. doi: 10.1038/natrevmats.2016.71

184. Zhang B, Huang J, Liu J, Lin F, Ding Z, Xu J. Injectable Composite Hydrogel Promotes Osteogenesis and Angiogenesis in Spinal Fusion by Optimizing the Bone Marrow Mesenchymal Stem Cell Microenvironment and Exosomes Secretion. Mater Sci Eng C Mater Biol Appl (2021) 123:111782. doi: 10.1016/ j.msec.2020.111782

185. Hu H, Dong L, Bu Z, Shen Y, Luo J, Zhang H, et al. Mir-23a-3p-Abundant Small Extracellular Vesicles Released From Gelma/Nanoclay Hydrogel for Cartilage Regeneration. J Extracell Vesicles (2020) 9(1):1778883. doi: 10.1080/20013078.2020.1778883

186. Shi Q, Qian Z, Liu D, Sun J, Wang X, Liu H, et al. Gmsc-Derived Exosomes Combined With a Chitosan/Silk Hydrogel Sponge Accelerates Wound Healing in a Diabetic Rat Skin Defect Model. Front Physiol (2017) 8:904. doi: 10.3389/fphys.2017.00904

187. Li L, Zhang Y, Mu J, Chen J, Zhang C, Cao H, et al. Transplantation of Human Mesenchymal Stem-Cell-Derived Exosomes Immobilized in an Adhesive Hydrogel for Effective Treatment of Spinal Cord Injury. Nano Lett (2020) 20(6):4298-305. doi: 10.1021/acs.nanolett.0c00929

188. Zhu D, Li Z, Huang K, Caranasos TG, Rossi JS, Cheng K. Minimally Invasive Delivery of Therapeutic Agents by Hydrogel Injection Into the Pericardial Cavity for Cardiac Repair. Nat Commun (2021) 12(1):1412. doi: 10.1038/ s41467-021-21682-7

189. Mardpour S, Ghanian MH, Sadeghi-Abandansari H, Mardpour S, Nazari A, Shekari F, et al. Hydrogel-Mediated Sustained Systemic Delivery of Mesenchymal Stem Cell-Derived Extracellular Vesicles Improves Hepatic Regeneration in Chronic Liver Failure. ACS Appl Mater Interfaces (2019) 11 (41):37421-33. doi: 10.1021/acsami.9b10126 
190. Turnbull MT, Zubair AC, Meschia JF, Freeman WD. Mesenchymal Stem Cells for Hemorrhagic Stroke: Status of Preclinical and Clinical Research. NPJ Regen Med (2019) 4:10. doi: 10.1038/s41536-019-0073-8

191. Lopa S, Colombini A, Moretti M, de Girolamo L. Injective Mesenchymal Stem Cell-Based Treatments for Knee Osteoarthritis: From Mechanisms of Action to Current Clinical Evidences. Knee Surg Sports Traumatol Arthroscopy Off J ESSKA (2019) 27(6):2003-20. doi: 10.1007/s00167-0185118-9

192. Razeghian-Jahromi I, Matta AG, Canitrot R, Zibaeenezhad MJ, Razmkhah M, Safari A, et al. Surfing the Clinical Trials of Mesenchymal Stem Cell Therapy in Ischemic Cardiomyopathy. Stem Cell Res Ther (2021) 12(1):361. doi: 10.1186/s13287-021-02443-1

193. Sharma D, Zhao F. Updates on Clinical Trials Evaluating the Regenerative Potential of Allogenic Mesenchymal Stem Cells in Covid-19. NPJ Regen Med (2021) 6(1):37. doi: 10.1038/s41536-021-00147-x

194. Shi M, Li YY, Xu RN, Meng FP, Yu SJ, Fu JL, et al. Mesenchymal Stem Cell Therapy in Decompensated Liver Cirrhosis: A Long-Term Follow-Up Analysis of the Randomized Controlled Clinical Trial. Hepatol Int (2021) 15(6):1431-41. doi: 10.1007/s12072-021-10199-2

195. Schacher FC, Martins Pezzi da Silva A, Silla L, Álvares-da-Silva MR. Bone Marrow Mesenchymal Stem Cells in Acute-On-Chronic Liver Failure Grades 2 and 3: A Phase I-Ii Randomized Clinical Trial. Can J Gastroenterol Hepatol (2021) 2021:3662776. doi: 10.1155/2021/3662776

196. Huang KC, Chuang MH, Lin ZS, Lin YC, Chen CH, Chang CL, et al. Transplantation With Gxhpc1 for Liver Cirrhosis: Phase 1 Trial. Cell Transplant (2019) 28(1_suppl):100s-11s. doi: 10.1177/0963689719884885

197. Kharaziha P, Hellström PM, Noorinayer B, Farzaneh F, Aghajani K, Jafari F, et al. Improvement of Liver Function in Liver Cirrhosis Patients After Autologous Mesenchymal Stem Cell Injection: A Phase I-Ii Clinical Trial. Eur J Gastroenterol Hepatol (2009) 21(10):1199-205. doi: 10.1097/ MEG.0b013e32832alf6c

198. Liang J, Zhang H, Zhao C, Wang D, Ma X, Zhao S, et al. Effects of Allogeneic Mesenchymal Stem Cell Transplantation in the Treatment of Liver Cirrhosis Caused by Autoimmune Diseases. Int J Rheum Dis (2017) 20(9):1219-26. doi: 10.1111/1756-185x.13015

199. Zhang Z, Lin H, Shi M, Xu R, Fu J, Lv J, et al. Human Umbilical Cord Mesenchymal Stem Cells Improve Liver Function and Ascites in Decompensated Liver Cirrhosis Patients. J Gastroenterol Hepatol (2012) 27 Suppl 2:112-20. doi: 10.1111/j.1440-1746.2011.07024.x

200. Lin BL, Chen JF, Qiu WH, Wang KW, Xie DY, Chen XY, et al. Allogeneic Bone Marrow-Derived Mesenchymal Stromal Cells for Hepatitis B VirusRelated Acute-On-Chronic Liver Failure: A Randomized Controlled Trial. Hepatol (Baltimore Md) (2017) 66(1):209-19. doi: 10.1002/hep.29189

201. Xu L, Gong Y, Wang B, Shi K, Hou Y, Wang L, et al. Randomized Trial of Autologous Bone Marrow Mesenchymal Stem Cells Transplantation for Hepatitis B Virus Cirrhosis: Regulation of Treg/Th17 Cells. J Gastroenterol Hepatol (2014) 29(8):1620-8. doi: 10.1111/jgh.12653

202. Salama H, Zekri AR, Medhat E, Al Alim SA, Ahmed OS, Bahnassy AA, et al. Peripheral Vein Infusion of Autologous Mesenchymal Stem Cells in Egyptian Hcv-Positive Patients With End-Stage Liver Disease. Stem Cell Res Ther (2014) 5(3):70. doi: 10.1186/scrt459

203. El-Ansary M, Abdel-Aziz I, Mogawer S, Abdel-Hamid S, Hammam O, Teaema S, et al. Phase Ii Trial: Undifferentiated Versus Differentiated
Autologous Mesenchymal Stem Cells Transplantation in Egyptian Patients With Hcv Induced Liver Cirrhosis. Stem Cell Rev Rep (2012) 8(3):972-81. doi: 10.1007/s12015-011-9322-y

204. Lanthier N, Lin-Marq N, Rubbia-Brandt L, Clément S, Goossens N, Spahr L. Autologous Bone Marrow-Derived Cell Transplantation in Decompensated Alcoholic Liver Disease: What Is the Impact on Liver Histology and Gene Expression Patterns? Stem Cell Res Ther (2017) 8(1):88. doi: 10.1186/s13287017-0541-2

205. Mohamadnejad M, Alimoghaddam K, Bagheri M, Ashrafi M, Abdollahzadeh L, Akhlaghpoor S, et al. Randomized Placebo-Controlled Trial of Mesenchymal Stem Cell Transplantation in Decompensated Cirrhosis. Liver Int Off J Int Assoc Study Liver (2013) 33(10):1490-6. doi: 10.1111/liv.12228

206. Wang L, Han Q, Chen H, Wang K, Shan GL, Kong F, et al. Allogeneic Bone Marrow Mesenchymal Stem Cell Transplantation in Patients With UdcaResistant Primary Biliary Cirrhosis. Stem Cells Dev (2014) 23(20):2482-9. doi: $10.1089 /$ scd.2013.0500

207. Wang L, Li J, Liu H, Li Y, Fu J, Sun Y, et al. Pilot Study of Umbilical CordDerived Mesenchymal Stem Cell Transfusion in Patients With Primary Biliary Cirrhosis. J Gastroenterol Hepatol (2013) 28 Suppl 1:85-92. doi: 10.1111/jgh.12029

208. Jang YO, Kim YJ, Baik SK, Kim MY, Eom YW, Cho MY, et al. Histological Improvement Following Administration of Autologous Bone MarrowDerived Mesenchymal Stem Cells for Alcoholic Cirrhosis: A Pilot Study. Liver Int (2014) 34(1):33-41. doi: 10.1111/liv.12218

209. Kabat M, Bobkov I, Kumar S, Grumet M. Trends in Mesenchymal Stem Cell Clinical Trials 2004-2018: Is Efficacy Optimal in a Narrow Dose Range? Stem Cells Trans Med (2020) 9(1):17-27. doi: 10.1002/sctm.19-0202

210. Sengupta V, Sengupta S, Lazo A, Woods P, Nolan A, Bremer N. Exosomes Derived From Bone Marrow Mesenchymal Stem Cells as Treatment for Severe Covid-19. Stem Cells Dev (2020) 29(12):747-54. doi: 10.1089/ scd.2020.0080

211. Shi MM, Yang QY, Monsel A, Yan JY, Dai CX, Zhao JY, et al. Preclinical Efficacy and Clinical Safety of Clinical-Grade Nebulized Allogenic Adipose Mesenchymal Stromal Cells-Derived Extracellular Vesicles. J Extracell Vesicles (2021) 10(10):e12134. doi: 10.1002/jev2.12134

Conflict of Interest: The authors declare that the research was conducted in the absence of any commercial or financial relationships that could be construed as a potential conflict of interest.

Publisher's Note: All claims expressed in this article are solely those of the authors and do not necessarily represent those of their affiliated organizations, or those of the publisher, the editors and the reviewers. Any product that may be evaluated in this article, or claim that may be made by its manufacturer, is not guaranteed or endorsed by the publisher.

Copyright $\odot 2022$ Wu, Fan, Wang, Shen, Zheng, Zhao and Yang. This is an openaccess article distributed under the terms of the Creative Commons Attribution License (CC BY). The use, distribution or reproduction in other forums is permitted, provided the original author(s) and the copyright owner(s) are credited and that the original publication in this journal is cited, in accordance with accepted academic practice. No use, distribution or reproduction is permitted which does not comply with these terms. 